\title{
Fortalezas de la Ribeira Sacra en el entorno del monasterio de Santo Estevo de Ribas de Sil
}

\author{
Rosario Valdés Blanco-Rajoy ${ }^{1}$
}

Recibido: 11 de abril de 2019 / Aceptado: 30 de marzo de 2020

Resumen. Tomamos como objeto de estudio un área geográfica de la margen izquierda del río Sil en su confluencia con el río Miño, que nos permite acercarnos al fenómeno de la fortificación del paisaje en el transcurso de la Edad Media. Contrastando la documentación escrita con el registro arqueológico, abordamos determinadas cuestiones que atañen a la evolución morfológica de los asentamientos fortificados, al papel que éstos pudieron jugar con relación a la ordenación territorial y también, al modo en que debieron interaccionar ciertas fortalezas que posiblemente fuesen coevas, cuyos enclaves se encontraban muy próximos entre sí.

Palabras clave: Galicia; Edad Media; territorio; fortalezas; tenencias; relaciones estratégicas.

\section{[gal] Fortalezas da Ribeira Sacra no contorno do mosteiro de Santo Estevo de Ri- bas de Sil}

Resumo. Tomamos como obxecto de estudo unha zona xeográfica da marxe esquerda do río Sil na súa confluencia co río Miño, que nos permite achegarnos ao fenómeno da fortificación da paisaxe no transcurso da Idade Media. Contrastando a documentación escrita co rexistro arqueolóxico abordamos determinadas cuestións que se refiren á evolución morfolóxica dos asentamentos fortificados, ao papel que poderían xogar en relación coa planificación territorial e tamén ao modo en que deberon relacionarse certas fortalezas que, estando moi próximas entre si, posiblemente funcionasen ao mesmo tempo.

Palabras chave: Galicia; Idade Media; territorio; fortalezas; tenencias; relacións estratéxicas.

\section{[en] Strongholds of the Ribeira Sacra in the Area Surrounding the Monastery of Santo Estevo de Ribas de Sil}

\begin{abstract}
The main purpose of the paper is a case study of a geographical area of the left bank of the River Sil at the confluence with the River Miño that allows us to approach the phenomenon of landscape fortification during the Middle Ages. Contrasting written sources with archaeological records, we address some issues in relation to the morphological development of fortified settlements, the role played in the management of the territory, and also how contemporary and nearby strongholds probably interacted.
\end{abstract}

Keywords: Galicia; Middle Ages; Territory, Strongholds; Tenures; Strategic Connections.

Sumario. 1. Introducción 2. El territorio de Búbal (siglos X-XI). 2.1. El castro de Litoria y las otras fortalezas del territorio altomedieval de Búbal. 3. La tierra y el castillo de Aguiar (siglos XII-XV). 3.1. Las otras fortalezas de la tierra de Aguiar. 3.2. La circunscripción de Santo Estevo de Ribas de Sil y el castillo de Penedos do Castro. 4. Conclusiones. 5. Referencias bibliográficas.

Como citar: Valdés Blanco-Rajoy, R. (2020): "Fortalezas de la Ribeira Sacra en el entorno del monasterio de Santo Estevo de Ribas de Sil", en Madrygal. Revista de Estudios Gallegos 23, pp. 375-399. 


\section{Introducción}

El marco de estudio elegido para la realización de este artículo abarca el entorno del monasterio orensano de Santo Estevo de Ribas de Sil, ubicado en la llamada "Ribeira Sacra", sobre la margen izquierda del río Sil, no muy lejos de su confluencia con el río Miño. En la Alta Edad Media este centro monástico aparece integrado en el antiguo territorio de Búbal que evoluciona compartimentándose en circunscripciones de menor extensión, comprendiendo la de Aguiar los cotos monásticos de Santo Estevo y de San Pedro de Rocas.

En esta área geográfica se localizan una serie de fortalezas que siguen siendo mayormente desconocidas, y que necesariamente hay que contextualizar en el espacio y en el tiempo. Por ello, los criterios metodológicos que aplicamos para profundizar en su estudio se basan no solo en el registro arqueológico de los asentamientos y de los vestigios arquitectónicos, sino también en el análisis histórico de los acontecimientos relacionados con las propias fortalezas y con el territorio en el que se enmarcan, que es soporte de las relaciones sociales, económicas y políticas que explican el encastillamiento ${ }^{2}$. En consecuencia, resulta preciso examinar y comprobar si los fenómenos experimentados en un reducido espacio se dan en un ámbito más amplio, estableciendo las posibles interacciones entre lo único, concreto y local con lo general.

El punto de partida ha sido la selección, análisis y vaciado de las fuentes documentales medievales y de la bibliografía especializada, además de las series toponímicas, cartográficas, y ortofotográficas, disponibles tanto en soporte analógico como digital. Asimismo, tuvimos en cuenta la revisión de los inventarios, informes y memorias de las intervenciones arqueológicas relativas a los asentamientos fortificados de la zona, de las que se desprenden una serie de elementos descriptivos susceptibles de ser abordados desde otras perspectivas que permitan llegar a la obtención de nuevos resultados.

La información así reunida fue contrastada sobre el propio terreno, al tiempo que se recabaron nuevos datos relativos a la identificación y localización de las fortalezas y a las características de sus emplazamientos y su entorno inmediato, prestando especial atención a condicionantes estratégicos como son la red de comunicaciones o la posible interacción con otros asentamientos próximos; igualmente se registraron los detalles relacionados con la edificación y disposición de las defensas, con su evolución y con las alteraciones estructurales que pudiera haber tanto de carácter sincrónico, vinculables con posibles reedificaciones, como de carácter diacrónico que pudieran responder a otras causas antrópicas y culturales.

Así pues, el procesamiento de toda esta información en su conjunto constituye la base sobre la que se apoya el presente trabajo.

\section{El territorio de Búbal (siglos X-XI)}

En el privilegio del año 921, por el que Ordoño II autorizó al abad Franquila la reconstrucción del monasterio de Santo Estevo de Ribas de Sil, se indica que estaba sito en el territorio de Búbal, provincia de la Galaecia, a orillas del Sil, hacia el puerto nuevo, entre los puertos de Xábrega y Pombeiro, bajo el castillo de Litoria ${ }^{3}$ (Vázquez Núñez 1900: 273; Duro Peña 1977: 247).

Sobre lo que fue el marco espacial correspondiente al territorio de Búbal y su posterior evolución a lo largo de la Edad Media, encontramos abundante información no solo en la documentación del monasterio de Santo Estevo, sino también en la de otros monasterios y prioratos repartidos por toda la geografía gallega y aún del norte de Portugal ${ }^{4}$, así como

2 Estos mismos criterios son los que en su momento se establecieron y aplicaron en el proyecto del Inventario Documental y Gráfico de las Fortalezas Medievales de Galicia, que se desarrolló en el seno del Instituto de Estudios Gallegos Padre Sarmiento de Santiago de Compostela, véase Pardo de Guevara, Olivera Serrano, González Paz y Valdés Blanco-Rajoy 2007: 115-139.

3 Sancto martiri primo Stephano que levita, quorum reliquie site sunt territorio Buualo, provintie Galletie, ripe Silis, ad portum Nobun, inter portos Sanabreca et Palumbario, subtus castello Litorie.

4 Cuando menos: San Pedro de Rocas, véase Duro Peña: 1972; San Salvador de Celanova, véanse Serrano y Sanz 1929, Díaz y Díaz, Pardo Gómez y Vilariño Pintos 1990, Andrade Cernadas 1995, Sáez Sánchez y Sáez Sánchez 1996 y 2000; Santa Comba de Naves, véanse Vázquez Núñez 1903, Duro Peña 1968; San Pedro de Ramirás, véase Lucas Álvarez y Lucas Domínguez 1988; Santa María de Ribeira, véase Sáez Sánchez 1944; Santa María de Oseira, véase Romaní Martínez 1989-2008; Santo Estevo de Chouzán, véanse Sáez y González de la Peña: 2003, Pichel Gotérrez 2009; San Xulián de Samos, véase Lucas Álvarez 1986; San Vicenzo de Pombeiro, véase Lucas Álvarez y Lucas Domínguez 1996; San Pedro de Vilanova de Dozón, véase Fernández de Viana y Vieites 2009; Santa María 
en las colecciones diplomáticas de las Iglesias de Lugo y Ourense ${ }^{6}$ y, también, en documentos reales correspondientes a los monarcas Alfonso $\mathrm{VII}^{7}$ y Alfonso IX ${ }^{8}$.

La implantación de este territorio puede verse como el reflejo de los cambios sociales $\mathrm{y}$ administrativos que se produjeron en el contexto del vasto proceso de ordenación y vertebración política del espacio, que se puso en marcha con la incorporación progresiva de nuevos territorios al reino astur?.

Desde la perspectiva del señorío, Búbal no conformaba por entonces una estructura territorial uniforme sino que, como consecuencia de las transferencias de poder que permitieron a la monarquía asegurar la fidelidad y el apoyo de los grupos sociales más influyentes, en ella se encontraban diversas circunscripciones sujetas tanto a particulares laicos, como a instituciones eclesiásticas, teniendo gran peso en la zona los dominios monásticos ${ }^{10}$. En este sentido destacaba indudablemente el monasterio de Santo Estevo de Rivas de Sil, pero sobre todo y muy por encima de todos los demás el de San Salvador de Celanova con sus prioratos y decanías dependientes.
El monasterio de Celanova fue fundado por el obispo san Rosendo, nieto del conde Hermenegildo Gutiérrez, e hijo de Gutier Menéndez, exponentes todos ellos de la más alta aristocracia de la época, a quienes los monarcas astures hicieron importantes concesiones en toda Galicia y en particular en torno al tramo final del Sil y a la parte media del Miño que comprendía el territorio de Búbal. Eran estos magnates, y otros como ellos, los que permitían establecer el nexo de conexión entre el poder del trono y la administración efectiva del territorio, desempeñando responsabilidades de gobierno. El conde Hermenegildo habría conseguido su hegemonía sobre el tramo medio del Miño venciendo, con los milites de palacio y con su propio ejército, a su rival el dux Vitiza que se había rebelado contra el rey Alfonso III (Isla Frez 1992: 139).

Los orígenes de la demarcación de Búbal pudieran rastrearse en circunscripciones territoriales anteriores ${ }^{11}$, relacionables en este caso concreto con topónimos de origen gentilicio. Así, los corónimos de los territorios altomedievales de Geurros, Tybris, Limie y Buualo presentes en la documentación, tienen clara

de Sobrado dos Monxes, véase Loscertales de G. de Valdeavellano 1976; Santa María de Fiães, véanse Ferro Couselo 1995, Marques 2016.

Véase López Sangil y Vidán Torreira 2011.

Véanse Duro Peña 1996, Vaquero Díaz y Pérez Rodríguez 2010.

Véase Recuero Astray, González Vázquez y Romero Portilla 1998.

Véase González González 1944.

El tramo medio del río Miño en torno a la ciudad de Ourense fue ocupado alrededor del año 865 por el futuro rey Alfonso III, promoviendo entonces la reconstrucción de la ciudad y restaurando su sede episcopal, véase Baliñas Pérez 1992: 106; la ciudad estaba enclavada en el corazón del territorio de Búbal.

10 Para hacerse una idea diremos que las comunidades monásticas que se documentan con cierta seguridad dentro de lo que debió ser la circunscripción alto medieval de Búbal, eran las de Santo Estevo de Chouzán (Carballedo), de San Xulián de Celaguantes (A Peroxa), de San Paio de Vilar (A Peroxa), de Santa María de Barra (Coles), de Santa María de Ucelle (Coles), de San Salvador y Santa María de Paradela (Coles), de San Salvador de Veiga (Coles), de San Xoán de Abruciños (Amoeiro), de Santa María de Amoeiro (Amoeiro), de San Vicenzo de Canedo (Ourense), de San Pedro de Cudeiro (Ourense), de Santa María de Melias (O Pereiro de Aguiar), de San Pedro de Triós (O Pereiro de Aguiar), de Santo Estevo de Ribas de Sil (Nogueira de Ramuín), de San Pedro de Rocas (Esgos), de San Vicenzo de Louredo (Toén) de Santa María de Castrelo de Miño (Castrelo de Miño), de San Salvador de Fegio (Castrelo de Miño), de San Salvador de Arnoia (Arnoia), de San Salvador de Paizás (Ramirás), de San Pedro de Ramirás (Ramirás), de San Paio de Rabal (Celanova), de Santo Tomé de Barxa (Celanova), de Santo Tomé de Veiga (Celanova), de Santa María de Vilanova (Celanova), de San Salvador de Celanova (Celanova), de Santa Baia de Berredo (A Bola), de San Pedro de Sorga (A Bola) y de Tructín (A Bola), véase Freire Camaniel 1998: 591, 598, 612, 631-632, 638, 667, 674-675, 685, 705, 709, 719-720, 755-756, 769, 805, 816, 818-819, 853-855, 866-870, 879-882, 929-930, 942, 946, 950-951, 955, 962. A parte, enclavado en el corazón del territorio se encontraba el coto viejo de la sede episcopal orensana, véase Pérez Rodríguez 2015: 242-243.

11 Para García de Cortázar el resultado aparente de los esfuerzos de encuadramiento de los nuevos espacios con que se acrecentó el reino astur a partir de la segunda mitad del siglo IX, fue precisamente la aparición en los textos de unos cuantos vocablos indicativos de unidades de agrupamiento administrativo como in suburbio, iuxta civitas, in termino o in territorio de, que parecen referirse a realidades socio-territoriales heredadas y ampliamente asumidas por las poblaciones de las comarcas en que tales palabras aparecen, mientras que otros términos implicaban novedad y así, desde el año 885 mandationes y commisos, son palabras que incluyen una idea de delegación. Piensa el autor que los reyes astures debieron crear unidades de agrupación en parte sobre la base de realidades sociales y físicas previas, en parte sobre la base de decisiones arbitrarias, con el objetivo de reunir administrativamente los recursos en un espacio determinado; véase García de Cortázar 2004: 282-283. 
correspondencia con los nombres de los populi y etnias indígenas prerromanas de los gigurri, los tibvri, los límici y los bibali, de cuya existencia dan cuentan diversos testimonios epigráficos y literarios ampliamente contrastados ${ }^{12}$. Todos ellos ocupaban espacios naturales (bien definidos y diferenciados por sus propios condicionantes geográficos) que hoy pertenecen a la provincia de Ourense, habiendo sido localizados los Gigurri en la comarca de Valdeorras, los tiburi en la de Trives, los límici en la de A Limia y los bibali en la de Ourense. Al comienzo de la era cristiana estos populi se organizaban en civitas, es decir, entidades territoriales mayores (por encima de las sub-comunidades de los castella, a los que englobaban), que estaban dotadas de núcleos capitales que funcionaron como centros gubernativos y económicos de los que serían ejemplo el Forum Gigurrorum, el Forum Limicorum y el Forum Bibalorum ${ }^{13}$.

Algunos autores abogan por retrotraer el origen del sistema organizativo que encarnan las civitas con anterioridad a la llegada de Roma (en relación con otras sociedades europeas de la segunda Edad del Hierro influidas por corrientes mediterráneas), al tiempo que plantean su reminiscencia en la Alta Edad Media (Pena Graña 1991: 102-103 y 2007: 57-88, García Quintela 2002: 74-79, 100-102).

En esta línea, la supervivencia de una toponimia arcaizante pudiera considerarse indicativa de un cierto grado de continuidad evolutiva con respecto a realidades espaciales anteriores, que comparten una misma base geográfica ${ }^{14}$. Sin embargo, no podemos obviar que los sucesivos procesos de reestructuración social, política y económica, acaecidos entre el cambio de era y el año mil, hacen que necesariamente los modelos de ordenación territorial que puedan rastrearse en un mismo ámbito espacial, tengan un significado sustancialmente distinto según nos refiramos a una u otra época. El cambio de semántica supondrá también una trasformación de la realidad física de dichas unidades organizativas y elementos articuladores.

Lo que en un plano general nos muestra la documentación medieval es que en el siglo $\mathrm{X}$ Búbal constituía un territorio integrado en el sistema político-administrativo del reino astur-leonés, al que servía de apoyo; abarcaba una extensión mucho más amplia de la tuvo en etapas posteriores, comprendiendo parte de las actuales comarcas naturales de Celanova y de la depresión de la cuenca del río Miño en torno a la ciudad de Ourense. Sus límites llegaban por el norte hasta los ríos de Fondós (Graulio en los documentos medievales) y Búbal, afluentes de la margen derecha del Miño que hoy se localizan en la provincia de Lugo, sobre la divisoria con la provincia de Ourense. Por el oeste llegaban hasta el río Barbantiño. Por el sur hasta el tramo medio y final de la cuenca del río Arnoia con sus afluentes de la margen izquierda Sorga y Tuño, bajo de los montes de Verea, y por el extremo este, donde se

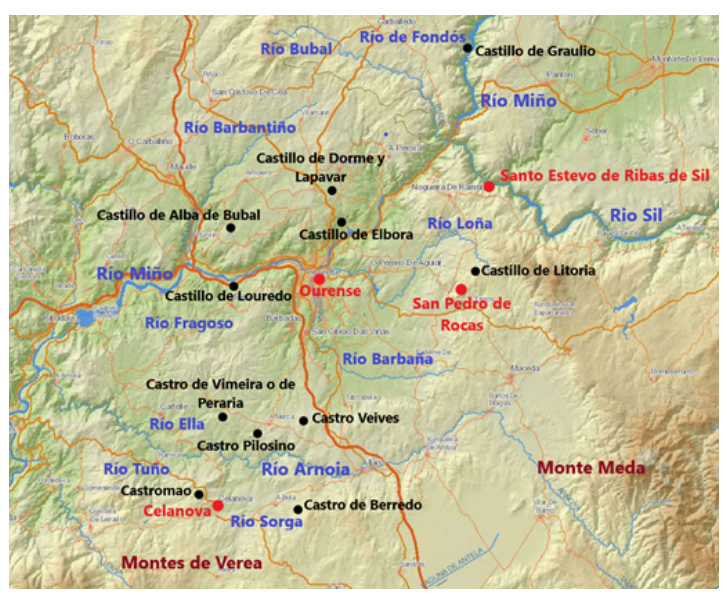

Mapa 1. Territorio y fortalezas de Búbal en la Alta Edad Media

12 Véase Balil Illana, Pereira Menaut y Sánchez-Palencia Ramos 1991: 32, 58-59, 66, 101.

13 La localización precisa del Forum Bibalorum está por determinar. En un principio Rodríguez Colmenero situó a los bibali en la cuenca del río Búbal afluente del Támega, cerca de Verín en la comarca orensana de Monterrei; posteriormente, reconsiderando su propia postura (compartida por otros autores como Taboada Chivite 1955: 476 y Tranoy 1981: 64), vino a conjeturar con la localización de la civitas de los Bibali en la comarca de Ourense, estableciendo su capital en el castro galaico romano de San Cibrao das Lás, ubicado sobre la margen derecha del Miño, entre las parroquias de San Cibrao das Lás y de San Xoán de Ourantes, en la divisoria de los ayuntamientos de San Amaro y Punxín, véase Rodríguez Colmenero 1977: 23-31 y 1997: 89-90. Por su parte, Pérez Losada considera que dada la relevancia que tuvo el núcleo de población romano de Ourense sería muy verosímil que asumiese funciones como capital de civitas, por lo menos en época bajo-imperial y tardía, véase Pérez Losada 2002: 156.

14 Determinados topónimos se transmitieron a través de la provincia eclesiástica galaica y así, en el siglo VI Geurros y Bibalos figuran en el listado de las parroquias inscritas en el territorio de la sede auriense contenido en el Parroquial Suevo, véase David 1947: 39. Estas mismas parroquias se vuelven a relacionar en la donación de las iglesias que Alfonso III concedió a la misma sede en el año 886, véase Castro y Martínez Sueiro 1923: 5-8. 
encontraban los monasterios de Santo Estevo de Ribas de Sil y de San Pedro de Rocas, hasta el tramo final del río Sil y las estribaciones de la sierra del Monte Meda, colindando ya con el territorio de Caldelas ${ }^{15}$ (mapa 1) ${ }^{16}$.

En documentos de carácter privado del tumbo de Celanova, donde era necesario precisar la localización de villas y propiedades, se mencionan otros territorios de menor extensión que estaban comprendidos dentro del ámbito espacial de Búbal que acabamos de describir, y que se restringían a los valles conformados por afluentes del Miño y del Arnoia, así como al tramo medio y final de este último río. Son los territorios de Petragio (Andrade Cernadas 1995: 484) en la cuenca el río Loña (ayuntamiento de O Pereiro de Aguiar), de Manzaneto o Manceneto (Ibid.: 128) en la cuenca del río Fragoso (ayuntamiento de Castrelo de Miño), de Elenia (Ibid.: 651) en la cuenca del río Ella (ayuntamiento de Cartelle), de Ravanal o Ravanale (Ibid.: 547, 539) sobre la margen derecha del río Arnoia, (ayuntamiento de Celanova), de Eires o Ayres (Ibid.: 384, 678) en la cuenca del río Tuño (ayuntamiento de Ramirás), de Sorice o Sorica (Ibid.: 69, 269, 360, 465, 467, 486, 490, 518-519, 521, 529, 579, 583, 607, 765, 780 ) en la cuenca del río Sorga (ayuntamientos de A Bola y Celanova) y de Arnogie (Ibid.: 6566, 131, 509, 534, 536-538, 540, 542-544, 548, $554,559,561,563,567,771)$ en la cuenca del río Arnoia (ayuntamientos de A Bola, A Merca, Celanova, Ramirás, Cartelle y Arnoia).

De todos ellos, nos interesa reseñar aquí toda noticia relacionada con lo que pudo ser el territorio de Petragio, ya que es el que afecta directamente al marco restringido de nuestra zona de estudio al estar localizado en torno al Loña, donde posteriormente surgirá la tierra de Aguiar, también llamada Aguiar de Petragio.

El territorio de Petragio se documenta en el año 1010 (Ibid.: 484). Dentro de sus términos, super rivulo Laonie, se encontraba la villa de Buarios (lugar de Boeiros, en la parroquia de Santa Marta de Moreiras, ayuntamiento de O Pereiro de Aguiar). En la misma feligresía de Moreiras se localiza el lugar de Pedraio, nombrado como Petragio en un documento del año 938, donde se dice que estaba en Búbal y que era cedido por Ilduara, madre de san Rosendo, al monasterio de San Salvador de Celanova (Ibid.: 18). En otro documento más del año 941 (Ibid.: 311) consta que el rey Ramiro II donó la villa de Petragio al obispo Rosendo y al monasterio de Celanova, íntegra, en todos los términos de su giro, encontrándose subtus oppido Litorie existente ${ }^{17}$. El mismo referente de localización se aplica a otros lugares próximos; así, en el año 942 el mismo rey Ramiro le encomendó al hermano de Rosendo, Froila Gutiérrez, el control de dos decanías en Búbal, una de ellas la de Tredones (Ibid.: 691). Al término de la misma centuria, entre los años 975 y 1011, figuran en la relación de las propiedades adquiridas por el prepósito Cresconio de Celanova, las villas de Tredones (actualmente lugar de Triós, parroquia de San Pedro de Triós, ayuntamiento de O Pereiro de Aguiar), que estaba subtus castro Litorie y de Armarici (lugar de Armariz, parroquia de San Cristovo de Armariz, ayuntamiento de Nogueira de Ramuín), que estaba igualmente en territorio de Bubalo, subtus castro Litorie discurrente rivulo Laonie (Ibid.: 291).

Como vemos la información muestra que Petragio, al igual que los otros territorios que nombramos más arriba, se revela como una realidad socio-territorial reconocible por la población local, con el peso y arraigo suficientes como para dar lugar en la Baja Edad Media a la formación de la tierra de Aguiar. No obstante, nada podemos decir en cuanto a si desempeñaba o no una función de ordenación pública ${ }^{18}$; lo cierto es que, tal como acabamos

15 Sobre lo que fue el espacio comprendido en el territorio de Búbal véanse Sáez Sánchez 1944: 168-169, Sánchez Pardo 2008: 54 y Pérez Rodríguez 2015: 243-247. Recientemente (2017) Mariña Bermúdez Beloso ha leído en la Facultad de Geografía e Historia de la Universidad de Santiago de Compostela una tesis doctoral que por el momento permanece inédita, y que bajo el título $O$ espazo do occidente peninsular e a súa organización territorial (ca. 700 - ca. 1250), afecta igualmente a este tema; véase https://dialnet.unirioja.es/servlet/tesis?codigo=146506 y http://cartulariosmedievales.blogspot.com/2017/08/nuevas-tesis-doctorales-sobre.html.

16 Base cartográfica del Ministerio de Agricultura y Pesca, Alimentación. Ministerio para la Transición Ecológica. Visores Geográficos, http://sig.mapama.es/id_tax/ [consulta: 20/06/2018].

17 En 1145 el rey Alfonso VII confirmó a Celanova el coto de Petragio, véase Recuero Astray, González Vázquez y Romero Portilla 1998: 113.

18 En el caso Eires además del territorio se documenta en el año 949 un comisso, véase Andrade Cernadas 1995: 376. Este vocablo, con connotaciones de poder, sí podría reflejar de forma efectiva y cierta la organización administrativa del reino teniendo al frente a algún magnate de la nobleza. 
de ver, cuando el rey cedió al monasterio de Celanova la villa de Petragio e hizo entrega al hermano de Rosendo del control de la decanía de Tredones, la unidad territorial de referencia que se cita es la de Búbal.

En el transcurso del siglo XI se observan notables readaptaciones que afectaron decisivamente a la organización de la estructura territorial de Búbal de forma que, al inicio de la centuria, la parte correspondiente a la margen izquierda del Miño pasó a formar parte del territorio de A Limia, volviendo a Búbal alrededor de los años sesenta del mismo siglo.

Pérez Rodríguez relaciona la causa de estas readaptaciones con las destrucciones normandas a principios del siglo XI y con las distintas coyunturas que en las siguientes décadas convulsionaron a la monarquía, alcanzándose un punto álgido con la fragmentación del reino originada por el fallecimiento de Fernando I y la reforma del espacio galaico por obra de su hijo García. Más tarde, se revela como un suceso de la mayor importancia para la reorganización de la zona meridional de Galicia, la concesión del condado de Portugal a Enrique de Borgoña por Alfonso VI en el año 1096, quedando Raimundo de Borgoña únicamente al frente del condado gallego (Pérez Rodríguez 2015: 245-246, 255-258). Tras este acontecimiento transcendental, la tierra de A Limia se convirtió en una zona fronteriza en disputa, experimentando nuevamente una reestructuración que vuelve a llevar su demarcación hasta la margen meridional del Miño, absorbiendo la parte que fue de Búbal ya de forma definitiva.

Todos estos hechos revelan profundos cambios en la concepción y percepción política del espacio, que harán que la situación sea ya distinta a comienzos de la siguiente centuria. Se inició entonces un proceso de compartimentación de los antiguos territorios, implantándose una nueva ordenación basada en tierras de menor extensión, que adquirieron protagonismo administrativo al ser concedidas a distintos delegados regios en régimen de tenencia ${ }^{19}$.

El número de estas tierras y sus tenentes se vino a multiplicar a lo largo de los siglos XII y XIII coincidiendo con un cierto fortalecimiento de la monarquía ${ }^{20}$. En este último período y en relación a lo que fue el ámbito espacial del antiguo territorio de Búbal, cuando menos se hace mención en la documentación a las tierras de Temes $^{21}$, Búbal ${ }^{22}$, Alba de Búbal ${ }^{23}$ y Castella de Búbal $^{24}$ sobre la margen derecha del Miño y a las tierras de Aguiar $^{25}$, Louredo ${ }^{26}$ y Sande ${ }^{27}$ sobre la margen contraria, estas dos últimas integradas ya en A Limia.

Las nuevas tierras llevarán en muchos casos el mismo nombre que se dará a las fortalezas que las encabezaban. Algunas de estas fortificaciones se construyeron ex- novo, mientras que otras veces se reedificaron los viejos castros y castillos altomedievales, que en esos momentos se habrían quedado obsoletos ante los avances de las técnicas poliorcéticas.

\subsection{El castro de Litoria y las otras fortale- zas del territorio altomedieval de Búbal}

Comprendidos dentro del propio territorio altomedieval de Búbal encontramos determinados castros y castillos que, cuando menos, jugaban cierto papel en relación a su espacio circundante funcionado como células de organización, ordenación y articulación del territorio (al igual que ocurría con villas y monasterios), al tiempo que ejercían el control militar del espacio, asumiendo la protección de los asentamientos poblados y de las explotaciones agropecuarias.

19 Sobre las tierras véase Jular Pérez-Alfaro 1991: 9-42.

20 Para Sánchez-Arcilla Bernal la introducción del régimen tenencial en Castilla y posteriormente en León, parece que obedeció a una reacción por parte de los monarcas al desmesurado poder que habían ido adquiriendo los condes en sus distritos y al deseo de asegurar mediante el sistema vasallático-beneficial la defensa del territorio; así el sistema de tenencias trajo consigo una fragmentación de los antiguos condados y mandaciones, con la intención por parte de los reyes de evitar que grandes distritos estuvieran en manos de un mismo magnate, véase Sánchez-Arcilla Bernal 2002: 29-30. Esta misma política se implantará desde un primer momento en el vecino reino de Portugal, véase Cardim, Fonseca y González Paz 2014: 237.

21 Documentada al menos desde el año 1213, véase González González 1944: II, 393.

22 Documentada al menos desde el año 1151, véase Recuero Astray, González Vázquez y Romero Portilla 1998: 148. Documentada al menos desde el año 1218, véase González González 1944: II, 475.

Documentada al menos desde el año 1138, véase Recuero Astray, González Vázquez y Romero Portilla $1998: 77$.

Documentada al menos desde el año 1136, véase Duro Peña 1972: 136.

Documentada al menos desde el año 1245, véase Cambón Suárez 1957: 1119-1120.

7 Documentada al menos desde el año 1212, véase Lucas Álvarez y Lucas Domínguez 1988: 186. 
Ya hemos visto cómo en relación con monasterio de Santo Estevo de Ribas de Sil y con el territorio de Petragio, se nombra repetidas veces la fortaleza de Litoria utilizando fórmulas o expresiones tales como, subtus castello Litorie, subtus castro Litoria, o bien, subtus oppido Litorie existente ${ }^{28}$.

Las mismas expresiones se aplican, en el mismo período, a los emplazamientos fortificados de Graulio (Sáez Sánchez y González de la Peña 2004: 181-183, Pichel Gotérrez 2009: 76) ${ }^{29}$, de Dorme y Lappa avar (Andrade Cernadas 1995: 333) ${ }^{30}$, de Lauretum (Ibid.: 662, 772) ${ }^{31}$, de Veives o Verves (Ibid.: 103, 105) ${ }^{32}$, de Pilosino o Pelosino (Ibid.: 39-40, 536-538, 542, 572) ${ }^{33}$, de Vimeira o Peraria (Ibid.: 595$596)^{34}$, de Berreto, Bisreto o Bisrredo (Ibid.: 25, 56, 134, 359, 371, 502, 509, 515) $)^{35}$ y de Castro Malo (Sáez Sánchez y Sáez Sánchez 1996: 113, Andrade Cernadas 1995: 130, 623,
697-698, 712) ${ }^{36}$, todos ellos igualmente emplazados en el territorio de Búbal, encontrándose relacionado el castro Pelosino con los sub-territorios de Arnogie y Rabanal y el castro Berreto con los de Arnogie y Sorice (mapa 1) ${ }^{37}$.

Se trata, sin duda, de referentes de localización pero, además, creemos que en estos casos al aludir a asentamientos fortificados y no a hitos geográficos sin más, puede ser también indicador de la existencia en el entorno de dichas fortalezas, de circunscripciones de tipo jurisdiccional ${ }^{38}$; así, en los términos de Litoria estarían integrados, cuando menos, el monasterio de Santo Estevo de Ribas de Sil con su coto, la decanía de Tredones, las villas de $\mathrm{Pe}$ tragio, Tredones y Armarici y el lugar de $\mathrm{Fe}$ larias (este último no identificado). Es decir, presumiblemente la circunscripción de Litoria compartiría un mismo espacio con el territorio de Petragio y aunque no encontramos nada

28 Otra referencia a esta fortaleza la encontramos en un documento del que Andrade Cernadas dice que sería posterior al año 916 y del que Sáez y Sáez dan como fecha probable el año 923, cuando Recesindo donó a Gutierre e Ilduara su ración en un busto situado en in monte Baron inter Bubale et Caldelas, super castro Litorie, in loco predicto Felgarias; véanse Andrade Cernadas 1995: 784-785 y Sáez Sánchez y Sáez Sánchez 1996: 83.

29 Documentado en el año 986. Se ubicaba sobre un peñasco conocido actualmente con el nombre de Penedo do Castelo que se alza sobre la margen izquierda del río Fondós, sobre su confluencia con el Miño, en el monte Graúllo o Garabullo, entre los lugares de Erbedeiro y Airoá, parroquia de San Pedro de Erbedeiro, ayuntamiento de Carballedo, provincia de Lugo.

30 Documentado en 1001. Localizado en el lugar de A Torre, parroquia de San Paio de Albán, ayuntamiento de Coles.

31 Documentado en los años 934 y 952 . Localizado sobre un pico llamado Pena Goia a unos 200 metros al oeste del castro romanizado de Louredo, en la parroquia de Santa María de Mugares, ayuntamiento de Toén.

32 Documentado en los años 989 y 1052 . Se localizaba en el llamado Monte Castrelo, en el límite con el antiguo territorio de A Limia, entre los lugares de Celeiros, San Victorio y O Castro, sobre la divisoria de las parroquias de San Pedro y de San Victorio da Mezquita y de los ayuntamientos de A Merca y Allaziz.

33 Documentado en los años 956, 960, 961, 997, 1011 y 1076. Aunque en este caso está por comprobar la existencia de un nivel de ocupación medieval en el correspondiente yacimiento, creemos que esta fortaleza se emplazaba en el monte de A Rodela, sobre los lugares de Rabal, San Paio y Faramontaos, entre las parroquias de San Salvador de Rabal y San Xes de Faramontaos, en la divisoria de los ayuntamientos de Celanova y A Merca.

34 Documentado en los años 1025 y 1027 . Localizado en el monte de A Rodeliña, a 500 metros al sudoeste del llamado Outeiro de Vimeiros, sobre el lugar de Doniz, parroquia de San Miguel de Espiñoso, ayuntamiento de Cartelle.

35 Documentado en los años 999, 1001, 1037, 1041, 1044, 1045, 1056 y 1063. Localizado en el monte del Castro de Berredo, sobre el lugar de Berredo, en la parroquia de San Miguel de Berredo, ayuntamiento de A Bola.

36 Documentado en los años 935, 986, 950 y 1039. Localizado sobre el lugar de Castromao, parroquia de Santa María de Castromao, ayuntamiento de Celanova.

37 Ya sin citar las expresiones de referencia, otras fortalezas altomedievales de Búbal que se nombran en los documentos son las de Elbora y Alba de Búbal. La fortaleza de Elbora está documentada en el año 986, véase Andrade Cernadas 1995: 303; se localiza junto al lugar de Seoane, en la parroquia de San Xoán de Coles, ayuntamiento de Coles. La fortaleza de Alba de Búbal está documentada en el año 1061, véase Andrade Cernadas 1995: 92; se localiza sobre la vertiente septentrional del monte Rodeiro en el sitio de O Coto do Castelo, entre los lugares de Albeiros y San Xiao, entre las parroquias de San Pedro de Trasalba y Santa Mariña de Fontefría, ayuntamiento de Amoeiro. Por otra parte, hemos encontrado en el territorio de Búbal otras fortalezas que, al no estar documentadas ni haber sido excavadas, no podemos adscribir con seguridad a la Alta Edad Media, aunque pudieran haber estado operativas por entonces; asimismo, no descartamos que algunas de las fortalezas que se documentan en el mismo territorio en la Baja Edad Media pudieran haber sido levantadas en un período anterior.

38 Del mismo modo, cuando encontramos la fórmula subtus ecclesie pensamos antes que nada en la circunscripción que pudiera corresponderle a tal iglesia, y no en lo que su edificación pudiera suponer como hito destacado del paisaje. Señala Isla Frez que es probable que los castros así mencionados, no solo fuesen una mera referencia geográfica, sino que además traducirían una relación con los habitantes del entorno, quienes deberían entregar allí prestaciones de todo tipo ya de orden militar, ya de recogida de impuestos; véase Isla Frez 1992:142. 
que nos indique que la fortaleza pudiera capitanear el territorio, cabría plantearse la posibilidad de que en realidad fuese asín ${ }^{39}$.

Tanto Litoria como Berredo y Castromao registran niveles de ocupación en la Prehistoria y en la Antigüedad; en Castro Veives ciertos indicios, aun por comprobar, podrían apuntar en este mismo sentido, mientras que las fortalezas de Louredo y Vimeira, sin estar levantadas sobre antiguos castros, se encontraban a su mismo pie.

Esta relación, que se constata también en otras áreas geográficas de la meseta leonesa y del norte de Portugal (Gutiérrez González 1995: 128-129; Ferreira de Almeida 1978: 47), parece obedecer tanto a condicionantes geoestratégicos como a cierto significado político, al haber podido constituir esos poblados antiguos centros de poder y de ordenación del territorio, recordándonos Isla Frez que el surgimiento del reino astur estaba ligado a un pasado indígena con unas características sociales propias, sobre el que se impusieron progresivamente elementos procedentes de la tradición visigótica (Isla Frez 1992: 130).

Por lo que respecta al territorio de Búbal, quizá el caso más llamativo sea el de Castromao, mencionándose en los documentos medievales tanto Castro Malo, como civitas Castro Magno (Andrade Cernadas 1995: 400) en alusión a un mismo núcleo que se ha venido identificando con Coeliobriga, la capital de la etnia indígena de los Coelerni al frente de los cuales figuran dos principes, padre e hijo, que se nombran en la llamada tessera de hospitalidad de Castromao. Coeliobriga desbordaba ya en época romana el asentamiento fortificado extendiéndose al llano, donde mantuvo una ocupación ininterrumpida hasta la actualidad. En la cima del propio castro se ha registrado un nivel medieval cuyo alcance real está todavía por precisar, y que en principio aparece asociado a la existencia de una pequeña ermita ya desaparecida (Fariña Busto 1991: 57-71; Orero Grandal 2000: 179-185).

Castro Veives constituye una mota terrera sobre un afloramiento rocoso, que da cabida en su cima a un reducto de planta oval que mide 25 por 10 metros, su altitud relativa con respecto al terreno circundante es de unos 9 metros; hay que tener en cuenta que las excavaciones furtivas y la extracción de canterías han minado partes de la mota, que en origen pudiera tener un mayor tamaño. En superficie no se observan restos de murallas, ni de ningún otro tipo de construcción, aunque si se encuentran sillarejos menudos entremezclados con fragmentos de cerámicas comunes de pastas grises y rojizas, con desgrasantes gruesos de cuarzo y mica, algunas de ellas de clara adscripción medieval. Por sus dimensiones esta mota solo podría dar cabida a un simple puesto castrense, donde pudiera haberse levantado alguna estructura defensiva construida en piedra, encontrando paralelismos en otras fortalezas medievales de Galicia, siendo el caso más conocido el de Caldaloba (en el ayuntamiento de Cospeito, provincia de Lugo) que conserva su torre.

El yacimiento de Castro Veives ha sido catalogado como un asentamiento fortificado de la Edad del Bronce y también medieval (Rodríguez Cao 1995: GA32047011); su adscripción a la Edad del Bronce se hizo en función de un conjunto de cerámicas encontradas en superficie, que tras un primer análisis parecían corresponder a esa época.

El castro de Berredo es de mayores dimensiones, con el perfil de una pequeña meseta, se asienta sobre un otero que se eleva unos 20 metros por encima del collado que lo une al terreno circundante; las pendientes se potenciaron con taludes artificiales de tierra que en algunos puntos alcanzan los 5 metros de altura. La cima acoge a un recinto de planta oval que mide 80 por 30 metros, estando defendido por un cercado terrero sobre el que pudo alzase una muralla pétrea, dada la cantidad de sillarejos que se acumulan sobre las laderas. En el extremo occidental del castro, sobre el perímetro de la cerca controlando el acceso, se encuentra lo que parece ser el derrumbe de una torre u otro tipo de bastión defensivo que se elevaría sobre un afloramiento rocoso, que constituye el punto más alto del asentamiento, donde se ven rebajes hechos para asentar una edificación y donde se amontonan escombros de tierra entremezclada con piedras.

39 Nos dice Gutiérrez González que en el siglo X la mayor parte de los distritos que se fueron creando en la meseta leonesa tenían su base territorial en lugares fortificados, donde se centralizaban las funciones gubernamentales ejercidas por los comites, habiéndose generado una red castral que jerarquizaba el poblamiento rural y lo integraba en la estructura político-administrativa del reino leonés (1995: 126-127). 
Orero Grandal adscribe Berredo a "época castreña" (Orero Grandal 2001: 155). Por nuestra parte diremos que, con independencia de la posible existencia aquí de un antiguo poblado, las referencias documentales llevan a pensar, con muy pocas dudas, que era este el solar de la fortaleza altomedieval de Berredo que pervivió hasta el final del medioevo ${ }^{40}$ y que parece haber jugado un papel importante en el control de los caminos, que pasando por sus inmediaciones, comunicaba la ribera del Miño con Allariz (Ferreira Priegue 1988: 169-170).

En cuanto al antiguo castro de Litoria, sabemos igualmente que se hallaba estratégicamente emplazado sobre un camino romano, que partiendo de Ourense enlazaba con la vía XVIII del Itinerario Antonino que iba de Braga a Astorga (García Rodicio 1977: 127; Pérez Losada 2002: 162-163). Este camino continuaba en uso en época medieval y a él se refiere el ya mencionado privilegio de Ordoño II, al detallar los términos del coto del monasterio de Santo Estevo de Ribas de Sil. Esta posición estratégica del emplazamiento de Litoria pudo contribuir a que fuese reutilizado en la Edad Media.

Es precisamente Litoria, uno de los yacimientos arqueológicos donde mejor se puede observar cómo su reocupación se limita prácticamente a un aprovechamiento y acondicionamiento de la infraestructura arquitectónica preexistente, reduciéndose la fortificación altomedieval a un recinto terrero que se acotó en la parte más alta y mejor protegida del antiguo castro.

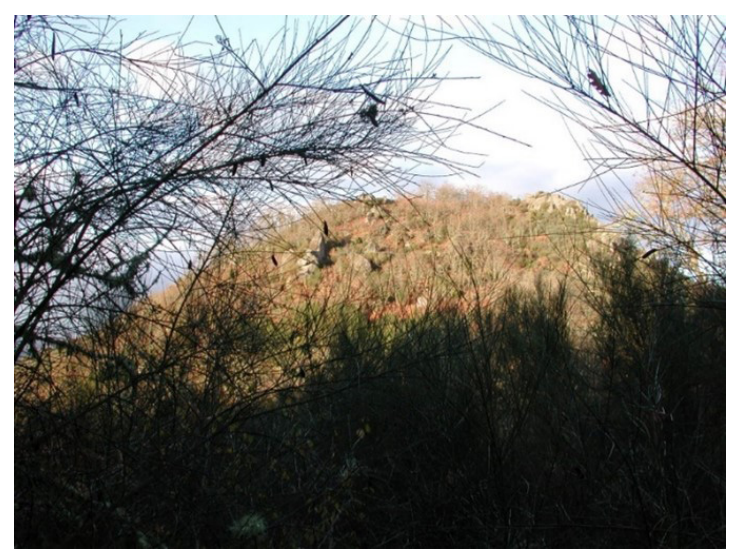

Imagen 1. Vista general del castro de Litoria
La fortaleza de Litoria se localiza en el llamado Monte do Castelo cerca del lugar de Arcos, en la parroquia de San Pedro de Rocas, ayuntamiento de Esgos $^{41}$. Se encumbraba en la cima de un otero rocoso que presenta acusadas pendientes en talud por todo su perímetro; su altitud relativa con respecto al territorio circundante es de unos 36 metros (imagen 1).

En la cumbre se pueden ver dos espacios bien diferenciados situados en distintos planos de nivel. El lado de mayor altura ocupa el extremo oriental de la cima donde se eleva una cresta rocosa; contra las peñas se amontonó de forma artificial una mota de tierra de unos 4 metros de altura mínima, que en su parte alta da cabida a un recinto de planta oval cuyo eje mayor en sentido norte-sur mide unos 40 metros de longitud y el eje menor en sentido este-oeste mide unos 10 metros de anchura; en superficie se ven escombros de tierra entremezclada con sillarejos graníticos. A la mota le precede un foso que la separa del resto del castro (imagen 2).

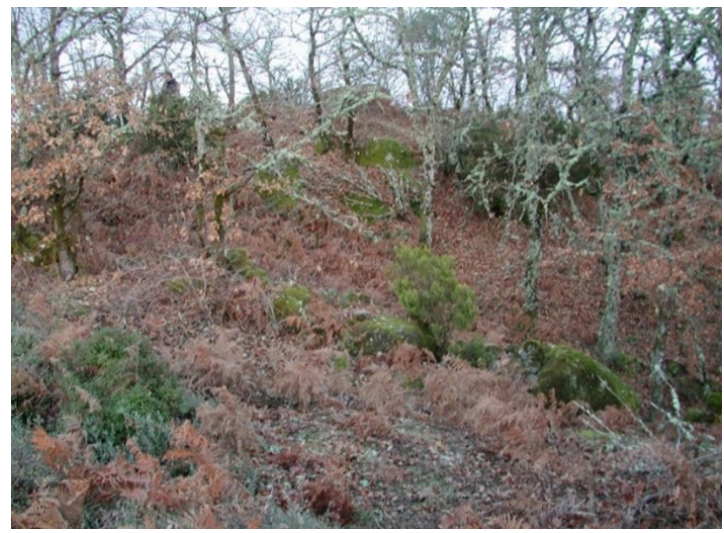

Imagen 2. Mota precedida por un foso en el interior del castro de Litoria

En un plano más bajo y hacia el oeste se extiende un segundo recinto, también de planta oval, que aparece explanado; su eje mayor de este a oeste mide unos 45 metros de longitud y el eje menor de norte a sur mide unos 25 metros de ancho. Este recinto estaba cerrado por una muralla de piedra construida con sillarejos de cara vista de pequeño y mediano tamaño, asentados en seco. La muralla se apoyaba en muchos puntos sobre la roca natural que aparece desmochada y nivelada a esos efectos,

40 Sobre la fortaleza medieval de Berredo véase González Paz 2007: 362-363.

41 Sobre el castro de Litoria y también sobre su localización véanse García Rodicio 1977: 122-127; Blanco González y Rodríguez Pereira 1991: 13-14. 
conservándose numerosos rebajes tallados que sirvieron para calzar su cimentación. La muralla está completamente derruida; sus canterías se extienden por las laderas del monte entremezcladas con la tierra. En el centro del recinto se encuentran los restos de una estructura que es conocida como "a mesa dos mouros", consistente en un prisma con forma de un cubo cuadrangular que fue tallado en la roca natural; en la parte superior del cubo se rebajaron tres cazoletas cuadradas y en su base se encuentran lo que parecen ser acanaladuras.

Blanco González y Rodríguez Pereira dicen que: "O lugar aparece cheo de buratos e marcas propias das construccións de madeira, así como de muros, fosos e abundante cerámica medieval" (Blanco González y Rodríguez Pereira 1991: 15). Según Seara, Cabo y Peralta, en el yacimiento se encontraron cerámicas castreñas de "superficies marrones y grisáceas, con fuerte desgrasante; fragmentos de tégulas y fragmentos de barro que pudieran corresponder a la pared de un hogar"; los autores inventarían el yacimiento como un asentamiento fortificado de la Edad del Hierro (Seara y Cabo 1986: GA32031002; Seara y Peralta 1989: GA32031002).

De las otras fortalezas altomedievales de Búbal que nombramos más arriba, sabemos que al menos Graulio, Alba de Búbal y Louredo fueron de realengo, revelándose como centros catalizadores del poder regio en medio de un paisaje preeminentemente rural, en el que la población se asentaba en pequeños enclaves dispersos y en el que ámbito urbano apenas tenía peso en a la ordenación territorial, siendo posible comprobar en el caso concreto de Louredo la existencia, ya desde la Alta Edad Media, de una demarcación propia sujeta al gobierno de la fortaleza de su nombre (Pérez Rodríguez 2015: 247).

En el caso de Graulio y Alba de Búbal las noticias están contenidas en un documento del año 1061, aunque se refieren a la rebelión del conde Nuño Rodríguez acaecida hacia el año 1050, cuando se alzó, junto con su madre Elvira y su abuela la condesa Odrocia, contra
Fernando I, con los castillos de Monte Roso, Gravulio, Alva de Buvale, et Novula, de los que el propio monarca dice expresamente que eran suyos, debiendo poseer el conde su tenencia por delegación regia; la rebelión de Nuño fue sofocada y sus propiedades familiares fueron repartidas por el rey entre sus leales, aplicándose supuestamente "la ley gótica"(Andrade Cernadas 1995: 92) (2. $^{42}$

En el caso de Louredo, para conocer mínimamente el alcance que pudo llegar a tener la fortaleza altomedieval, hay que acudir a documentos de principios del siglo XII, ya que es por entonces cuando nos consta que era de realengo, entregándola Alfonso VII a la sede episcopal auriense en 1133, con todo lo que allí le pertenecía y había pertenecido a sus abuelos los reyes de Hispania y debiera pertenecer a sus sucesores, esto es, con todo su honore, hombres, heredades y derechos, y con todos los foros que a él se le debieran hacer (Recuero Astray, González Vázquez y Romero Portilla 1998: 42-48), de este modo las tierras que hasta entonces gobernaba el castillo pasaron a conformar el coto nuevo de Ourense. De las sucesivas ampliaciones del coto otorgadas por el propio Alfonso VII, reconstruye Pérez Rodríguez cuál fue espacio que había estado sujeto al castillo. Según este autor la parte oriental de la demarcación le habría sido segregada y entregada ya a la sede auriense por Alfonso III, hacia el año 900 (Pérez Rodríguez 2015: 247-255, 258-259).

En el mismo momento en que hizo sus concesiones, Alfonso VII dejó bien fijados los deberes militares que a partir de entonces tendrían los hombres de Louredo para con la corona, estableciendo que de tener que guerrear solo lo harían dentro de los términos concretos de A Limia que se especifican en el correspondiente documento ${ }^{43}$, y en caso de que el mismo Alfonso o cualquiera de sus sucesores quisieran hacerles prestar servicio sería en Galicia y por un plazo limitado de veinte días.

Las tres fortalezas realengas de las que venimos hablando pervivieron hasta el final del medioevo, momento en que el castillo de Graulio

42 Odrocia comitissa (...) revellavit nobis cum filia sua Gyloira et cum nepus suum comitem monnium ruderici in nostros castellos Monte Roso, Gravulio, Alva de Buvale, et Novula, seditiones et scandalum mittens in terra Galletie, ob cuius astucia fraudulenta persequimur illum et fugiente in montibus iuditio Dei a nostris militibus comprehensus vinculis retrudi iussimus. Bona et eorum omnia lex nobis gotica abere iussit ut ex ea ordinaremus quod gloria mea iuberet. Véase también Sánchez Candeira 1999: 122-123.

43 Usque in Montem de Ramo et usque in pomar de deos el usque in penam de cegulos et usque terminum inter Barroso el Limiam et inde usque ad Mineum; véase Recuero Astray, González Vázquez y Romero Portilla 1998: 45. 
pertenecía (según declaraciones de los testigos del Pleito Tabera-Fonseca) al conde Lemos, habiendo sido derrocado durante las revueltas "irmandiñas" por la hermandad de Chantada y Camba (Rodríguez González 1984: II, 502).

Hasta donde sabemos, Alba de Búbal continuó siendo de realengo a lo largo de la Baja Edad Media, conociéndose los nombres de algunos de los tenentes que tuvieron la tierra y el castillo por delegación regia en los siglos XII y XIII (González González 1944: II, 63, 194; Duro Peña 1968: 173; Romaní Martínez 19892008: I, 343, 358, 389, 446, 581, 616, 703; II 745).

En el mismo período el castillo de Louredo se mantuvo en manos de la sede auriense. Es en el año 1245 cuando encontramos la primera noticia referente a la tierra de Louredo, que se menciona en un documento de venta que hizo Sancha Gómez al monasterio de Melón de dos medios casares en Toén y Mugares, de los que se dice expresamente que estaban en dicha tierra; aparece como firmante tenente Castellum Velasco Fernandi de Morariis (Cambón Suárez 1957: 1119-1120). En los años 1225 y 1242 este caballero figura como tenente de Castro Ramiro ${ }^{44}$ (Vaquero Díaz y Pérez Rodríguez 2010: I, 339 y II 106) y en 1246, en otro documento del monasterio de Melón, vuelve a aparecer cómo merino en Louredo por mano del obispo de Ourense (Cambón Suárez 1957: 1167). En 1258 consta que era tenente de la tierra de Louredo, Gonzalo Rodríguez (Vaquero Díaz y Pérez Rodríguez 2010: II, 259); las referencias a esta misma tierra se vendrán a repetir en la siguiente centuria (Enjo Babío 2018: I, 239, 803).

\section{La tierra y el castillo de Aguiar (ss. XII-XV)}

Como ya hemos anticipado, el reparto en 1096 de los condados de Galicia y Portugal entre Raimundo y Enrique de Borgoña, casados res- pectivamente con las infantas Urraca y Teresa, hijas del rey Alfonso VI, constituyó un acontecimiento decisivo en lo que a la reorganización del espacio comprendido al norte y sur del río Miño se refiere. Este río se convirtió entonces en divisoria entre ambas unidades políticas, faltando todavía un tiempo para que se consolidase el reino de Portugal y se firmasen los correspondientes tratados por los que se fijó la frontera entre ese reino y la corona de Castilla y León, que en lo que concierne a la provincia de Ourense acabó estableciéndose bastante más allá del Miño, sobre una línea extendida al sur de la cabecera del Támega, afluente de la margen derecha del río Duero, y del río Salas, afluente de la margen izquierda del Limia.

Sería Raimundo de Borgoña quien integraría definitivamente en A Limia la parte del antiguo territorio de Búbal que comprendía la margen izquierda del Miño (Pérez Rodríguez 2015: 258); esto sería así al menos en lo que respecta a los espacios correspondientes a las cuencas fluviales de los afluentes Barbaña, Fragoso y Arnoia, este último en su tramo final desde el entorno de Celanova hasta su desembocadura.

Tanto el territorio de A Limia como los de Toroño y Baroncelle, le serán disputados por la mujer de Enrique de Borgoña, Teresa, y por su hijo Alfonso Enríquez. Señalan Cardim, Fonseca y González Paz, que ambos consideraban tales espacios como partes irredentas del conglomerado político portugués, existiendo por su parte una intencionalidad expansiva que ejercieron con capacidad política y militar contra las tierras gallegas. Las conquistas portuguesas efectuadas por entonces se hicieron efectivas a través del dominio de las fortalezas, estando todas ellas bajo un comando único delegado, desempeñando esa función en la comarca limiana de Ourense el conde Vasco Sánchez de Barbosa (Cardim, Fonseca y González Paz 2014: 236-237) ${ }^{45}$.

44 Castro Ramiro o Castel Ramiro fue fortaleza de los obispos de Ourense ubicada en las afueras de la ciudad en los términos del coto viejo, en el monte llamado de O Castelo, entre los lugares de O Castelo, A Costa, Cabeza de Vaca y A Carballeira, en la parroquia de Santa Eufemia do Centro de Aforas, ayuntamiento de Ourense. La encontramos documentada por primera vez en el año 1201; véanse Duro Peña: 1996: 41, Vaquero Díaz y Pérez Rodríguez 2010: I, 210. El castillo de Louredo se emplazaba a unos 4 kilómetros de distancia de Castro Ramiro en dirección oeste.

45 Así, en la crónica conocida como Vida y milagros de San Rosendo se dice que el rey Alfonso Enríquez ordenó edificar con buenos sillares el castillo de Berredo, dentro del coto de Celanova y que se lo entregó en tenencia al conde Velasco (probablemente el susodicho Vasco Sánchez) quien, a su vez, lo delegó en su merino de nombre Alfonso Bos; se dice en la misma crónica que el castillo estuvo en pie por dos años y que fue destruido por orden del rey Fernando II de León, véase Díaz y Díaz, Pardo Gómez y Vilariño Pintos 1990: 187-193. En el año 1130 , antes de que hubiese reedificado este castillo, Alfonso Enríquez ya había donado a Sancho Rodríguez los casales de Ramondo y Gaindi, junto con todo el realengo habido entre Berredo, Pardavedra y Castrosando: Ego infans 
Es en el contexto de esta coyuntura política y territorial cuando encontramos la primera noticia referida a la tierra de Aguiar, cuya existencia se documenta en 1136, siendo entonces su tenente Diego Yáñez (Duro Peña 1972: 136). Desde esa fecha hasta finales del siglo XIV se conoce una larga lista de los que fueron tenentes de Aguiar, primero por delegación regia y, a partir de 1238 por mano de los arzobispos compostelanos, ya que el rey Fernando III les donó la circunscripción en ese mismo año (Duro Peña 1972: 120-121, 123-124; 1977: 269, 273, 277-278, 287; González González 1944: II, 299).

Gran parte de los datos correspondientes son proporcionados por las cláusulas de datación de los documentos de los monasterios de San Pedro de Rocas y de Santo Estevo de Ribas de Sil, lo que ya de por sí indicaría que la demarcación constituía una unidad territorial de referencia política y administrativa, hecho que se ve plenamente ratificado al haber estado gobernada por distintos delegados regios que aparecerán igualmente como tenentes del castillo de Aguiar de Pedraio ${ }^{46}$.

La tierra de Aguiar se localizaba sobre la cuenca del río Loña, espacio que como ya hemos visto constituía el extremo nororiental del territorio de Búbal, en el que todavía a finales del siglo XII parece estar integrada. Así en el año 1185, cuando la abadesa de Lobanes hizo donación al monasterio de San Pedro de Rocas de diversos bienes, se indica que Rocas estaba en territorio buvalense, bajo el monte Barón y el castro de Litoria, entre los ríos Loña y Esgos; figura en el mismo documento Fernando Arias, tenente de Aguiar (Vázquez Núñez 1901: 378-379; Duro Peña 1972: 139) ${ }^{47}$.

Hay constancia documental de que la tierra de Aguiar comprendía determinados lugares como Laioso (Duro Peña 1972: 136), en la parroquia de Vilar de Ordelles, ayuntamiento de Esgos; la iglesia y el coto de San Cristovo de Armariz (Duro Peña 1977: 251), en la parroquia del mismo nombre, ayuntamiento de Nogueira de Ramuín; el lugar de Toxedo, en San Miguel do Campo, perteneciente al mismo ayuntamiento y la feligresía de Sabadelle, en el ayuntamiento de O Pereiro de Aguiar (Bouzas Rosende 2016: 202, 472). Con todo, la información es insuficiente para reconstruir los términos de lo que debió ser la demarcación de la tierra, por lo que Duro Peña se acerca a esta cuestión recurriendo a una comparación con la delimitación realizada en siglo XIV de lo que fue el arciprestazgo de Aguiar (Duro Peña 1972: 119-120). En líneas generales, viene a resultar que Aguiar abarcaba (en todo o en parte) los actuales ayuntamientos de Esgos, Nogueira de Ramuín y O Pereiro de Aguiar, comprendiendo los antiguos cotos monásticos de Santo Estevo de Ribas de Sil y de San Pedro de Rocas, además de los de Velle (perteneciente al monasterio de Rocas), de Pedraio

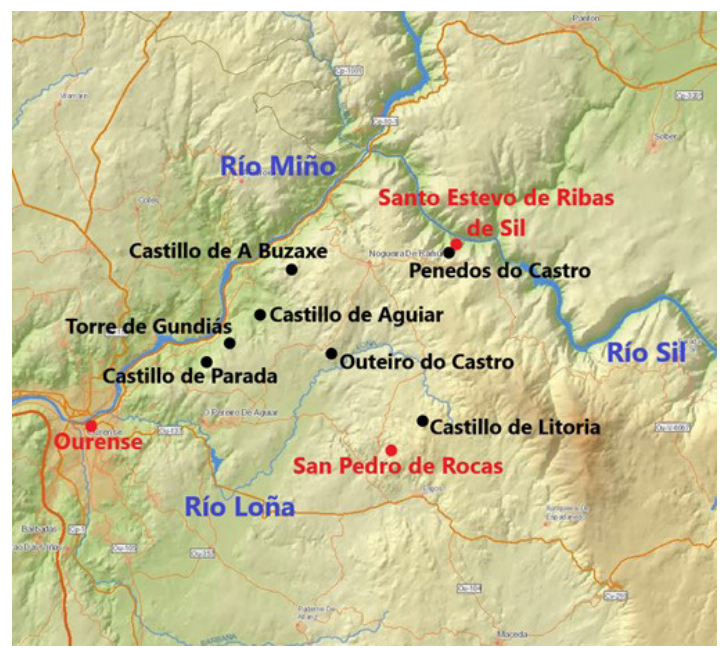

Mapa 2. Tierra y fortalezas de Aguiar en la Baja Edad Media

Adefonsus filius Henrici et nepos Adefonsi Yspanie regis, tibi Santio Rodrigiz facio et concedo kartam donationis et firmitatis de nostra hereditate quam vocant casal de Ramondo, et alia que vocatur Gaindi, toto illo regalendo quod est inter Berredo et Parada Vedra et Castrusando, discurrente arrugio Berredo, subtus mons Calvus; véase Andrade Cernadas 1995: 372.

46 Es sabido que con las tenencias los delegados regios asumían determinadas competencias como las de vigilar y cumplir la ley, intervenir en prendas y pesquisas, velar por el orden público, o percibir y administrar parte de los tributos recaudados en su jurisdicción, siendo lo primordial la defensa de la tierra y del propio reino acudiendo a la llamada del rey; véase González González 1944: I, 343-347. De todo ello se derivaban beneficios militares, ingresos económicos y privilegios políticos que en este caso concreto son difíciles de determinar.

47 Donnis sanctisque martiribus apostolorum Petri et Pauli quorum baselica ab antiquitus sita est territorio buvalense, subtus monte Baron et castro quod nuncupant Litorie, inter rivulos Laiona et Alesgos et alpes ibidem prolixas et plures et ipso monasterio de Sancto Petro quod nuncupant Rocas. Por el privilegio concedido por Alfonso VI en 1153 a dicho monasterio sabemos que los cotos de Rocas y de Santo Estevo de Ribas de Sil eran colindantes per radicem de Lidoira et inde ad petram de Lidoira; véase Duro Peña 1972: 137. 
(perteneciente al monasterio de Celanova) y, tal como acabamos de ver, de Armariz (perteneciente al monasterio de Santo Estevo) (mapa $2)^{48}$.

El castillo de Aguiar, también llamado de Aguiar de Pedraio y más tarde castillo de A Cidá, encabezaba la tierra de su mismo nombre cumpliendo funciones jurisdiccionales propias de un sistema de tenencias. Se emplazaba sobre el afloramiento de un promontorio rocoso aislado de todo núcleo de población, en el lugar que hoy se llama A Torre da Cidá ubicado entre las poblaciones de Gundiás, Penela y Ventosela, en la parroquia de San Miguel do Campo, ayuntamiento de Nogueira de Ramuín (imagen 3).

Desde ese lugar hacia el norte y el oeste existe una amplia visibilidad sobre el Miño; en concreto sobre el tramo del río ubicado al nordeste de la ciudad de Ourense, dominándose desde la fortaleza los puertos fluviales y el camino principal que remontaba la corriente en dirección a Monforte de Lemos (Ferreira Priegue 1988: 151, 159-160 y mapa anexo de la provincia de Ourense).

La morfología de la fortaleza se supeditó a las condiciones del emplazamiento, que constituye un pequeño otero rocoso de unos 19 metros de altitud relativa con respecto al terreno circundante; el punto de unión del otero con el cordal que se eleva a sus espaldas se sitúa al sudeste.

La cima acoge un recinto de planta circular que no mide más de 15 metros de diámetro. Este recinto está rodeado en todo su perímetro

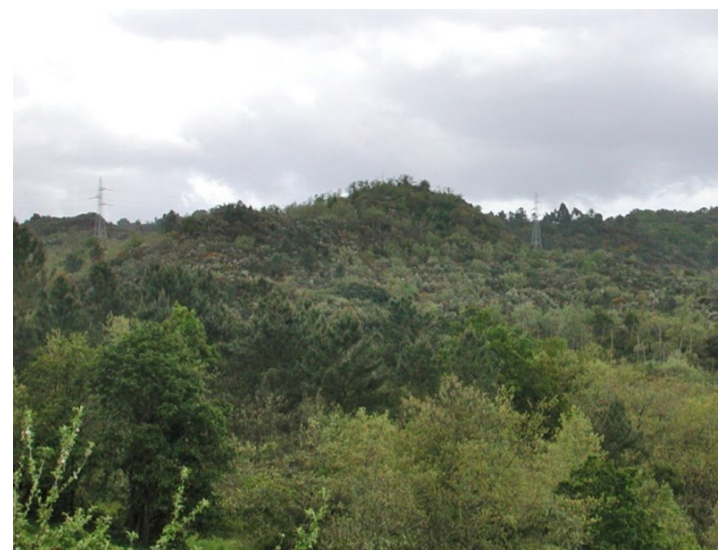

Imagen 3. Emplazamiento de A Torre da Cidá, antiguo castillo de Aguiar de Pedraio por tres terrazas que se escalonan sobre las laderas, multiplicando el espacio edificable. Es posible apreciar todavía los restos de los lienzos rectilíneos correspondientes a las cortinas de las murallas, que fueron construidas con mampuestos de granito asentándose sobre la roca natural, así como las cimentaciones de otras estructuras de habitación cuyos derrumbes se acumulan en el interior de la fortaleza, junto con abundantes fragmentos de tejas y de cerámicas comunes, mayormente de adscripción medieval. El acceso a la fortaleza estaba defendido por un gran foso excavado en el sector sudeste del asentamiento.

El yacimiento ha sido inventariado como fortaleza medieval por Romalde Purriños y González Méndez (Romalde Purriños y González Méndez 1991: GA32052015) y como un castro romanizado fortificado de nuevo en la Edad Media por Eguileta Franco y García Valdeiras (Eguileta Franco y García Valdeiras 1997: GA32052015).

Nos consta que en 1198 Alfonso IX otorgó en dote a la reina Berenguela el castillo de Aguiar de Pedraio, que lo tenía en ese momento Gonzalo Yáñez (González González 1944: II, 194), y no mucho después, en 1206, figura nuevamente entre otras fortalezas de Galicia ofrecidas como garantía por el propio Alfonso IX en el tratado de Cabreros (Ibid.: II, 285).

Cuando en 1214 este mismo rey confirmó los privilegios del coto jurisdiccional del monasterio de Santo Estevo, quedaron claramente establecidas las limitaciones de los ricos-hombres de la tierra y de los que tuviesen el castillo de Aguiar, a los que se les prohibió la entrada en el coto; tampoco, podían tener allí encomienda alguna, estando sus moradores liberados de asistirles en lo militar y en lo económico (Ibid.: II, 412; Duro Peña 1977: 259).

Tres años más tarde, el castillo de Aguiar de Pedraio permanecía asignado a la reina $\mathrm{Be}$ renguela, por lo que el rey lo excluyó expresamente de la dote otorgada a sus hijas Sancha y Dulce (González González 1944: II, 449). Sería su hijo y sucesor Fernando III quien en 1238 lo cediese a perpetuidad a la Iglesia compostelana, contando con el beneplácito de su madre. El monarca concedió entonces el castillo con la tierra y su honor y con su alfoz y con todos sus derechos y pertenencias,

48 Base cartográfica del Ministerio de Agricultura y Pesca, Alimentación. Ministerio para la Transición Ecológica. Visores Geográficos, http://sig.mapama.es/id_tax/ [consulta: 20/06/2018]. 
quedando eximido de la potestad del merino regio al igual que ocurría en el resto de la tierra de Santiago, debiendo observarse a partir de ese momento las costumbres de la demarcación compostelana (González Balasch 2004: 254-255) $)^{49}$.

Vemos en el correspondiente documento el empleo de los términos terra, honore y alfoz, sin que podamos discernir si en realidad son sinónimos relacionados con una sola circunscripción jurisdiccional, o si por el contrario de lo que se está hablando es de jurisdicciones distintas y de diferente rango tanto por su extensión, como por su rentabilidad económica; en cualquier caso, el término alfoz parece referirse aquí a la demarcación territorial estricta del castillo, que no tendría por qué ser necesariamente asimilable a la delimitación global de la tierra.

Durante esta etapa los arzobispos compostelanos cedieron la posesión y el control de la fortaleza de Aguiar a sucesivos caballeros que deberían jurarles fidelidad y así sabemos que en 1283 la tuvo Esteban Fernández de Castro, señor de Lemos y pertiguero mayor de la tierra de Santiago (Duro Peña 1972: 158; González Vázquez 1996: 193) ${ }^{50}$. Este magnate difícilmente pudiera haber ejercido personalmente sus funciones como tenente de Aguiar siendo lo más probable que, a su vez, delegase en terceros.

En 1309 nos consta que llevaban esta misma tierra Elvira Pérez, viuda de Nuño González de Novoa, y su hijo Juan Pérez de Novoa, tras haberla recibido del arzobispo Rodrigo de Padrón, quedando obligados como vasallos del arzobispo a la prestación de ayuda militar en contrapartida por el disfrute de su beneficio (González Vázquez 1996: 221).

En el Libro de la remenbrança de rentas e derechos del arzobispado de Santiago (14351436) aparece relacionada la tierra de Aguiar y el "castillo que llaman la Çidad", que estaba embargado entonces por García Díaz de
Cadórniga; así mismo consta que las rentas, fueros y derechos que al prelado correspondían por la tierra las llevaba Fernán Eáns de Soutomaior, lo que suponían 15.000 maravedíes anuales (Rodríguez González 1991: 148).

Sostiene López Ferreiro que hacia el año 1460 la tierra de Aguiar le sería entregada en feudo al tercer conde de Benavente, Alonso Pimentel Enríquez, por parte del arzobispo de Santiago Rodrigo de Luna, en pago por el apoyo que le prestó frente al conde de Trastamara que le tenía tomada la ciudad de Compostela (López Ferreiro 1904: 236). Más tarde, Alonso Pimentel dejaría a su hijo Juan Pimentel todo lo que poseía en Galicia. Así, según declaraciones de un testigo del pleito Tavera-Fonseca, Juan Pimentel era el dueño del "castillo de la çiudad", que había sido destruido por la Hermandad junto con la fortaleza del "castillo Ramiro", "porque dellas se azian males y robos en el dicho reino e las gentes del y tanbien porque acogían en ellas los que hazian los dichos males e porque dezian que heran casas nuevas, enpero quel testigo no sabe si heran nuebas o viejas si no" (Rodríguez González 1984: II, 487).

Finalmente, Juan Pimentel acabó por incorporar definitivamente Aguiar a su patrimonio personal, al incluirlo en la fundación de mayorazgo que otorgó con licencia de los Reyes Católicos en 1498. El mayorazgo comprendía, además de la tierra de Aguiar con la fortaleza y "sitio de la Çiudad", los cotos, villas, alfoces y fortalezas de Sandiás, Allariz, Milmanda y O Bolo (García Tato 2001: 46).

\subsection{Las otras fortalezas de la tierra de Aguiar}

Sabemos gracias a la prospección arqueológica que en un radio menor de 3 kilómetros en torno al castillo de Aguiar existieron otras cuatro fortalezas medievales que son los castillos de Parada, A Buzaxe, O Tombo, también conocido como Torre de Gundiás y Outeiro do Castro.

49 Dono itaque vobis et concedo castellum meum quod vulgaliter appellatur Aguillar de pedrayo, cum terra et honore suo et cum suo alfoz et cum ómnibus directturis et pertenenciis suis; quecumque ego ibi habeo et habere debeo ut illud vos vestrisque successores iure hereditario perpetuo habeatis et irrevocabiler possideatis. Denique castellum a potestate maiorini eximo sicut tota alia terra Santi Iacobi exempta dignoscitur et in hac parte illa consuetudine gaudeat que in tota alia terra Sancti Iacobi actenus exititit observata.

50 Según nos dice González Vázquez, de lo que percibían los prelados de Santiago por las tierras se descontaba una cantidad en metálico, la reteença, que se pagaba a los beneficiados por las tenencias para que se ocupasen de mantener los castillos en buenas condiciones, abastecidos y dotados con una guarnición suficiente que garantizase sus funciones defensivas. 
La fortaleza de Parada se alzaba sobre un pico rocoso conocido con el nombre de O Castelo que se ubica a unos 500 metros al norte del lugar de Parada, en la parroquia de San Bieito da Veiga, ayuntamiento de O Pereiro de Aguiar (imagen 4). Estaba defendida gracias a las fuertes pendientes naturales que rodean el emplazamiento por todos los lados excepto por el sudeste, donde un collado une el pico con el cordal montañoso que se encuentra a sus espaldas constituyendo la parte más accesible; la altitud relativa entre el collado y la cima es de 15 metros.

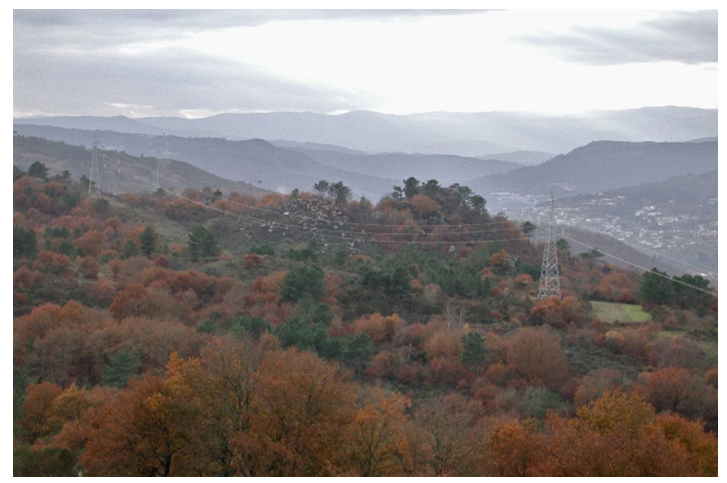

Imagen 4. Emplazamiento del castillo de Parada

La cima alberga un exiguo espacio de 10 por 20 metros, en el que aflora un batolito al que se accede por una serie de melladuras talladas en la roca que funcionan a modo de precarios escalones; la roca se ve desmochada y rebajada para cimentar sobre ella. En la ladera existe una terraza que se extiende hacia el lado este, alcanzando una anchura máxima de 20 metros. Todo el lugar, desde la cumbre al pie, aparece cubierto por escombros de tierra entremezclada con abundantes fragmentos de tejas y cerámicas comunes medievales.

Este yacimiento fue inventariado por Rodríguez Cao y García Valdeiras en 1999 (GA320 58006).

El castillo de A Buzaxe se encontraba igualmente sobre un espolón rocoso, sito en el extremo suroeste del monte de Liñares, conocido con el nombre de O Castelo o Penedo dos Mouros, ubicado a unos 300 metros al noroeste del lugar de A Buzaxe, en la parroquia de San Xosé de Carballeira, ayuntamiento de Nogueira de Ramuín (imagen 5). La cumbre del pico sobre el que se alzaba se encuentra desmochada, albergando un recinto de forma oval que del nordeste al sudoeste mide unos 20 metros de longitud y del noroeste al sudeste unos 10 metros. El pico está rodeado en todo su perímetro por fuertes pendientes que lo defienden de forma natural; por el norte se alza unos 15 metros por encima del terreno circundante con paredes casi verticales, mientras que por el suroeste el desnivel es de 25 metros. El punto de unión con el cordal del monte se sitúa al noroeste. Existe un único acceso extremadamente difícil que se abre paso entre los afloramientos de granito a través de unas estrechas escaleras. Así mismo, se observan rebajes tallados en las rocas, habiendo en la cumbre una inscripción epigráfica precedida de una cruz, en la que únicamente se lee con total claridad la palabra ERA, siendo los demás caracteres de difícil interpretación o imposible lectura $^{51}$.

Este yacimiento figura como un asentamiento fortificado medieval en las fichas del Inventario Arqueolóxico da Xunta de Galicia (Romalde Purriños y González Méndez 1991: GA32052019; Eguileta Franco y García Valdeiras 1997: GA32052019).

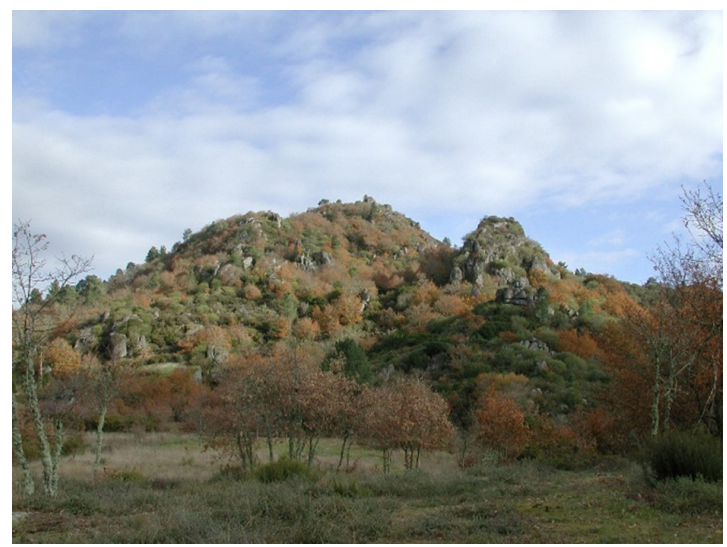

Imagen 5. Emplazamiento del castillo de A Buzaxe

La fortaleza de O Tombo o de A Torre se levantaba sobre un otero rocoso sito a unos 200 metros al oeste del lugar de Gundiás, en la parroquia de San Miguel do Campo, ayuntamiento de Nogueira de Ramuín (imagen 6). La altitud relativa del otero con respecto al terreno circundante es de unos 20 metros; las pendientes son más acusadas hacia el noroeste, siendo más accesible la parte contraria. La cima del

51 Con todo García Valdeiras (2013: 46) ofrece la siguiente lectura: UEDIS CLOS ERA MLXXV (Vedis acotó en la era 1075, es decir año 1037). 
otero da cabida a un recinto de planta oval que de norte a sur mide unos 5 metros de largo y de este a oeste unos 10 metros de ancho. Rodea la cima una terraza que en el lado oeste alcanza una anchura máxima de 15 metros. En las rocas aparecen rebajes y pequeñas cazoletas que se hicieron para cimentar y sustentar estructuras hoy desaparecidas. Sobre las laderas se ve gran acumulación de escombros.

O Tombo figura igualmente como un asentamiento fortificado medieval en las fichas del Inventario Arqueolóxico da Xunta de Galicia (Romalde Purriños y González Méndez 1991: GA32052017; Eguileta Franco y García Valdeiras 1997: GA32052017).

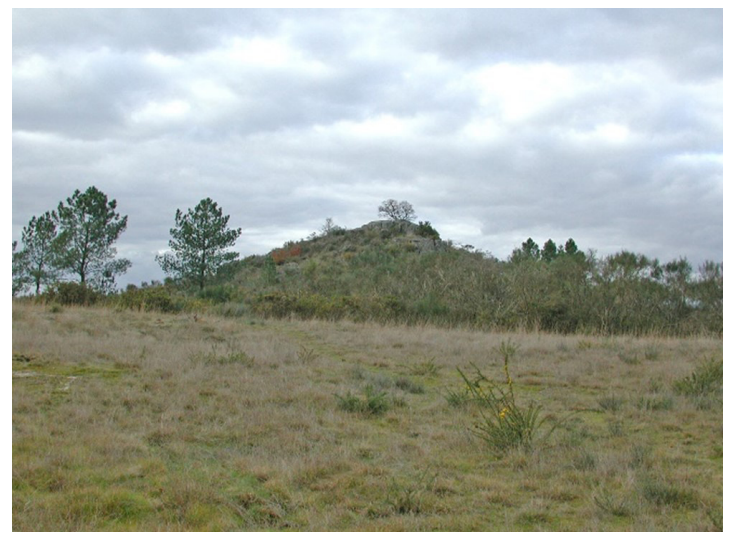

Imagen 6. O Tombo de Gundiás

La fortaleza de Outeiro do Castro se localiza a unos 300 metros al este del lugar de O Bión, en la parroquia de Santa María de Faramontaos, ayuntamiento de Nogueira de Ramuín. Constituye una mota de unos cinco metros de altura, encumbraba sobre un otero rocoso ubicado en la margen derecha del río Loña (imagen 7). El otero se une al territorio circundante por el lado nordeste, habiendo una notable caída hacia el fondo del valle por el lado sur-sudoeste. La cima de la mota configura un recinto explanado, que de norte a sur mide unos 35 metros y de este a oeste unos 30 metros. En superficie, aparecen tejas y fragmentos de cerámica común mezclada con escombros de tierra

En las fichas del Inventario da Xunta de Galicia Outeiro do Castro aparece como un asentamiento fortificado de la Edad del Hierro (Romalde Purriños y González Méndez 1991: GA32052001; Eguileta Franco y García Valdeiras 1997: GA32052001). Por nuestra parte pensamos que la morfología del yacimiento, que constituye una mota similar a otras que se levantaron en el transcurso del medioevo, y lo exiguo del espacio edificable hacen que este emplazamiento sea más apropiado para establecer un puesto militar y no un poblado castreño, para el que materialmente apenas habría cabida.

Esta última fortificación se encontraba en la margen de una vía principal de la Edad Media que iba de Ourense a la tierra de Lemos, por Pereiro de Aguiar, Malburguete y Luintra, para bajar a la barca de Pombeiro en el río Sil, mientras que los castillos de Parada, A Buzaxe y O Tombo, al igual que el castillo de Aguiar, se alzaron como altas atalayas sobre el reborde montañoso de la margen izquierda del Miño, controlando desde la distancia tanto los puertos fluviales, como el camino que iba de Orense a Monforte remontando el río Miño (Ferreira Priegue 1988: 151, 160-161 y mapa adjunto de la provincia de Ourense).

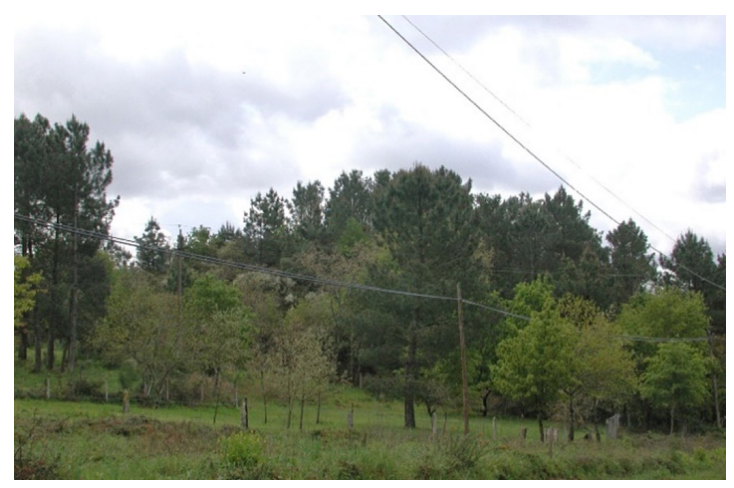

Imagen 7. Outeiro do Castro

Estas cuatro fortalezas, que se adaptaron en todo caso a las condiciones naturales de los emplazamientos en altura sobre los que asentaban, son de muy modestas dimensiones constituyendo con toda probabilidad simples puestos castrenses que no permitirían acoger grandes contingentes militares.

Los emplazamientos de las fortalezas de Parada, A Buzaxe y O Tombo conservan el topónimo "Castelo" que recuerda su antiguo carácter y que rara vez se relaciona con un poblado castreño. Sus características son muy similares, por lo que cabría pensar que fuesen todas ellas construidas ex-novo más o menos dentro de un mismo período comprendido en el transcurso del medioevo, habiendo podido funcionar coetáneamente.

No hemos hallado referencias documentales de ninguna de estas fortalezas, aunque sabemos que Outeiro do Castro se ubicada sobre el propio límite del coto del monasterio de Santo Estevo de Ribas de Sil, como debía estarlo también el castillo de A Buzaxe. 
Tal concentración de fortificaciones en un espacio relativamente reducido es un fenómeno nada usual en Galicia, aunque se registran casos parecidos tanto en el ámbito peninsular, como en otros países europeos donde nos dice Mora-Figueroa que, al menos desde el siglo XI hasta el siglo XV, se dan ejemplos de castillos erigidos muy próximos entre sí y con un uso simultáneo, obedeciendo casi siempre a diversas causas legales o sociológicas, y rara vez a conveniencias poliorcéticas (Mora-Figueroa 1994: 78-80).

Visto lo que acontece en otras áreas del propio reino castellano (Sánchez-Arcilla Bernal 2002: 27) y dada la morfología de estas pequeñas fortificaciones, cabría la posibilidad de que existiese una relación de subsidiaridad o dependencia respecto al castillo de Aguiar y su circunscripción. Otra explicación posible que diese razón de su existencia es que simplemente encabezasen tierras privilegiadas por habitar en ellas algún caballero o rico-hombre de los que como, ya hemos visto, se documenta un grupo notorio en esta zona en torno al año 1214. En este mismo año consta también que el abad de Santo Estevo había presentado querella contra Diego Yáñez, milite de Gundiás y contra otros milites de la tierra de Aguiar que edificaban casas, compraban heredades y hacían vasallos en el coto del monasterio (Duro Peña 1977: 257).

Con respecto a estas últimas cuestiones, no hay que olvidar que la tierra de Aguiar fue en todo caso señorío de los arzobispos de Santiago quiénes, por privilegio exclusivo otorgado por el rey Fernando II en 1180, disfrutaban de la prerrogativa de levantar fortalezas dentro del territorio de su jurisdicción, de modo que ningún noble podía poseer torre o fortificación alguna sin su consentimiento y el de la iglesia compostelana (López Ferreiro 1975: 182-186).

Es un hecho sabido que se permitió la construcción de fortalezas ajenas dentro del señorío compostelano en diferentes épocas y a diversos miembros de la nobleza con los que en determinados momentos interesaba estrechar lazos y establecer alianzas, reconociendo siempre la supremacía de los arzobispos a los que necesariamente se debía prestar pleito-homenaje. Señala González Vázquez que por lo general los caballeros que solicitaban el permiso arzobispal solían ejercer un poder que deseaban fortalecer a través de una construcción emblemática, no siempre de excepcional utilidad desde el punto de vista del dominio del territorio, pero sí con una dimensión ideológica de representación del poder y de su delegación, ya que a menudo las peticiones provenían de aquellos que previamente disfrutaban de algún préstamo concedido por los propios prelados (González Vázquez 1996: 188).

\subsection{La circunscripción de Santo Estevo de Ribas de Sil y el castillo de Penedos do Castro}

Como ya hemos ido viendo, todavía en la segunda mitad del siglo XII y hasta comienzos del siglo XIII aparece nombrada la fortaleza de Litoria como referente de localización de propiedades y lugares y también, para establecer la situación del monasterio de San Pedro de Rocas y los límites de su coto en la divisoria con el de Santo Estevo de Ribas de Sil (Recuero Astray, González Vázquez y Romero Portilla 1998: 168; Duro Peña 1972: 139 y 1977: 256). Presumiblemente, Litoria jugaría por entonces un papel tangencial con respecto a la tierra de Aguiar, ya que estaba presidida por el castillo homónimo.

Precisamente en el último cuarto del siglo XII nos encontramos con un delegado regio, Velasco Fernández, que en 1188 confirmó una concesión otorgada por Alfonso IX intitulándose tenente del Bierzo, con Robreda y Santo Estevo de Ribas de Sil (González González 1944: II, 32; González Balasch 2004: 203), de lo cabe deducir que cuando menos en ese momento coexistían en torno al monasterio de

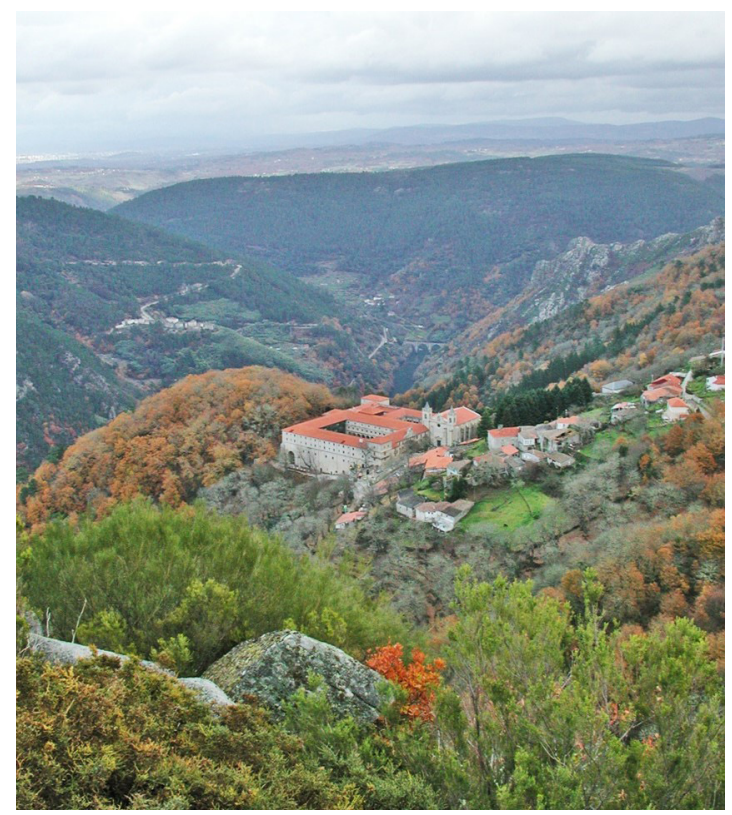

Imagen 8. Vista del monasterio de Santo Estevo de Ribas de Sil y de la tierra de Lemos desde el castillo de Penedos do Castro 
Santo Estevo dos jurisdicciones distintas, una de carácter regio y otra de carácter señorial y eclesiástico, correspondiente esta última al coto monástico.

De nuevo el registro arqueológico nos confirma que no era Litoria la única fortaleza enclavada sobre dicho coto, ya que existía otro castillo emplazado en un pico rocoso conocido con el nombre de Penedos do Castro, que se alzaba sobre la fábrica del propio monasterio de Santo Estevo dominándolo por completo. El pico se localiza en el monte de As Trapas a unos 400 metros al norte del lugar de Pombar, en la parroquia de Santo Estevo de Ribas de Sil, ayuntamiento de Nogueira de Ramuín; un antiguo camino de carro de unos tres metros de anchura, que conserva todavía el empedrado en los tramos de pendiente, discurre entre el castillo y el monasterio.

Desde Penedos do Castro se podía divisar hacia el lado del nordeste un importante tramo del río Sil y de los antiguos pasos que lo cruzaban en dirección a la tierra de Lemos (Castillo López 1930: 283-287; García Rodicio 1977: 132-133; Ferreira Priegue 1988: 167), siendo posible contemplar igualmente la propia ciudad de Monforte de Lemos y la sierra de O Caurel (imagen 8); por los restantes lados la visión se reduce a los montes que rodean el emplazamiento.

El yacimiento de Penedos do Castro fue identificado por primera vez como una fortaleza medieval por Ángel del Castillo (1930: 277-287). Lo inventariaron Romalde Purriños y González Méndez en 1991 (GA32052006) y Eguileta Franco y García Valdeiras en 1997 (GA32052006). Este último lo excavó en los años 1999, 2000 y 2001, realizando una última campaña de consolidación en el 2007. De los trabajos efectuados se concluye la existencia de un poblado castreño que registra dos fases diferenciadas de ocupación entre los siglos IV y I a.C; así mismo, se pudo constatar que, tras un período de abandono, se levantó sobre el antiguo castro una fortaleza medieval (García Valdeiras 2013: 33-35).
Rodríguez Colmenero (1995: 233-237) habla de la existencia de tres inscripciones epigráficas grabadas en las rocas que despuntan en la cumbre de este yacimiento; una de ellas, ya conocida y publicada previamente por diversos autores, contiene el nombre de Leovigildo siendo de probable datación visigoda (Castillo López 1930: 278-281; Arias Sanjurjo 1932: 10-11, 26-29; José Freire Camaniel 1988-89: 133-142; Blanco, Dorribo y Rodríguez 1992: 12; Rodríguez Colmenero 1995: 233-237).

El pico sobre el que se asentó la fortaleza de Penedos do Castro tiene una altura relativa con respecto al territorio circundante de unos 19 metros (imagen 9). Está defendido por fuertes pendientes naturales que lo hacen inaccesible por todos sus lados excepto por el sudoeste, donde se encuentra una vaguada que es punto de unión con el monte que se eleva a espaldas de la fortaleza, constituyendo un padrastro.

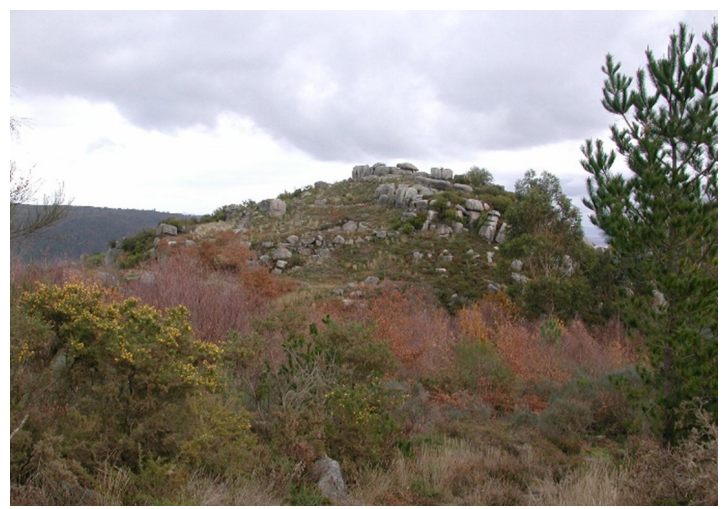

Imagen 9. Emplazamiento del castillo de Penedos do Castro

En la cima del asentamiento las rocas despuntan formando una pared natural hacia el lado nordeste, la superficie restante constituye un recinto explanado de planta oval cuyos ejes miden unos 15 metros de norte a sur, por unos 5 metros de este a oeste. Cerraba este recinto una muralla hecha con sillarejos de granito con cara vista de la que sobresale un cubo de forma semicircular que mide 3 metros y medio de diámetro ${ }^{52}$ (imagen 10). En este recinto alto

52 De la línea meridional de la muralla que a media ladera cerraba la fortaleza de Arauxo sobresalían dos cubos de planta semicircular que medían unos $3 \mathrm{~m}$ de diámetro. De uno de ellos únicamente se conserva el rebaje practicado en la roca para asiento de su cimentación. El otro cubo mantiene todavía en pie las primeras hiladas del muro, siendo en todo muy similar al que se encuentra en Penedos do Castro. En el caso de Arauxo, este segundo cubo se superpuso a los cimientos de una muralla anterior rompiendo con su antiguo trazado, de modo que estamos ante el caso claro de una obra de remodelación y reedificación destinada a potenciar la defensa activa de la fortaleza, que consiste básicamente en atacar desde cubos de flanqueo para defender los tramos de muralla con total cobertura de tiro entre cubo y cubo. En términos de Mario Barroca, es éste uno de los avances fundamentales que caracteriza al 
se recuperaron durante los trabajos de excavación algunos clavos y escorias de fundición de hierro, que podrían indicar la existencia de un pequeño taller metalúrgico (García Valdeiras 2013: 36-37).

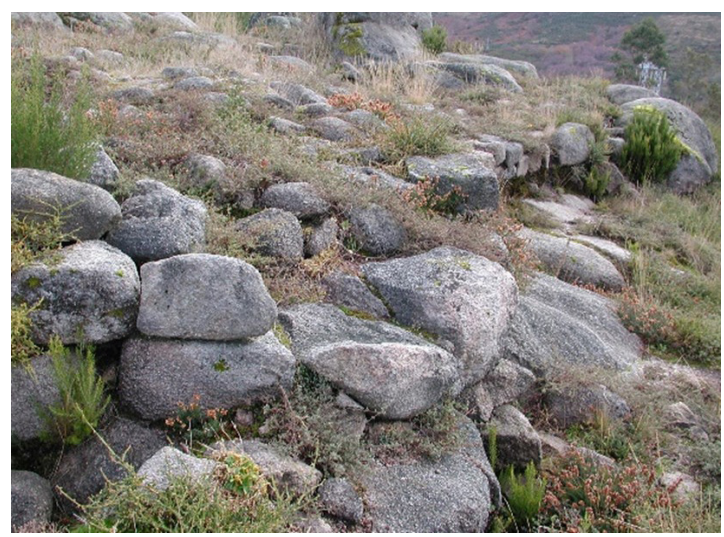

Imagen 10. Detalle del cubo de muralla que sobresale en la cima de Penedos do Castro.

A media ladera se extiende hacia el sudoeste un segundo recinto que mide unos 20 metros de este a oeste, por unos 10 metros de norte a sur. Aquí se encontraron restos de un pavimento y de una estructura construida con argamasa de arcilla y entramado vegetal, que parecen corresponder al primer nivel de ocupación del castro datado por el método del carbono 14 entre los siglos IV y II a.C. (Ibid.: 41).

Este segundo recinto esta defendido por una línea amurallada que por el lado sur flexiona y asciende por la pendiente para ir a cerrar por debajo de la cima; en ese punto la muralla tiene una anchura de 2,30 metros. Sus lienzos tanto por el lado de dentro como por el exterior están igualmente construidos con sillarejos graníticos de tamaño medio y pequeño con cara vista, trabados con barro; el corazón de la estructura está constituido por tierra entremezclada con pequeñas piedras. Hacia el lado oeste la misma muralla se asienta sobre grandes bloques ciclópeos apenas desbastados, que aparecen retranqueados sobre un muro más bajo construido con sillarejos graníticos y mortero de barro.

De la fortaleza medieval de Penedos do Castro tampoco encontramos noticia alguna en la documentación. No obstante, cabe preguntarse si tanto esta fortaleza, como la de Litoria, podrían haber actuado como centros de aplicación del poder en la jurisdicción regia de Santo Estevo de Ribas de Sil. Lo cierto es que siendo esto posible, la falta de información no nos permite asegurar nada al respecto, aunque sí se podría pensar que, aun cuando no cumpliesen con funciones públicas, sí ejercerían necesariamente el control militar sobre sus respectivos espacios, que suponemos tendrían que estar bien diferenciados.

Menos probable, por ser un hecho inusual, es que Penedos do Castro presidiese el coto monástico de Santo Estevo; de haber sido así, extraña la total ausencia de noticias en la correspondiente documentación. En cualquier caso, una fortaleza que supuestamente le fuese ajena al monasterio, al estar enclavada sobre su propia fábrica debió ser una fuente de incomodidad para sus abades, si no de conflicto y confrontación directa, como nos consta que hubo con los milites de la propia tierra de Aguiar por ingerir indebidamente en la jurisdicción del coto.

\section{Conclusiones}

En suma, lo que vemos a través del estudio de caso es que no se pueden entender las fortalezas medievales sin considerar los procesos de organización del territorio. Ambos elementos constituyen factores de un binomio, por el que el control de las fortalezas suponía el control efectivo del territorio de donde provenían todo tipo de recursos, tanto materiales como humanos, sobre los que se sustentaba el poder. 
En las diversas circunscripciones que surgieron y en algunos casos coexistieron compartiendo un mismo espacio en el entorno geográfico de Santo Estevo de Ribas de Sil, vemos que se levantaron distintas fortificaciones que necesariamente debieron ejercer competencias derivadas de la jefatura militar, al tiempo que actuaron como elementos articuladores del territorio. Nos consta, ya desde la Alta Edad Media, que algunas de estas fortificaciones fueron de realengo cumpliendo también con funciones públicas de carácter jurídico y administrativo, siendo cabeceras gubernativas que en principio estuvieron en manos de condes y magnates.

En este sentido no es casual la elección de los emplazamientos que aúnan valores estratégicos y significancia política, pudiendo establecerse cierta relación entre determinadas fortalezas altomedievales y poblados castreños de la prehistoria y la antigüedad, que fueron en su momento centros de poder o que pudieron tener cierta relevancia respecto a la organización territorial.

Hablamos en su conjunto de fortalezas que se encontraban diseminadas en medio de un paisaje preeminentemente rural y que mayormente se alzaban aisladas, desligándose físicamente de los caseríos y lugares que solía haber en sus proximidades. Por lo general disfrutaban de un amplio dominio visual sobre buena parte del territorio circundante, controlando especialmente las vías de comunicación y los cursos fluviales con sus pasos y puertos, ya que se emplazaban sobre las crestas y picos rocosos de los montes o en oteros y altozanos evitando los fondos de valle. Así pues, la eficacia y operatividad militar se basaba fundamentalmente en la defensa pasiva aprovechando la situación de ventaja que proporcionaba emplazarse en puntos altos, de modo que las edificaciones se adaptaron a los condicionantes orográficos, aunque el espacio fortificado se individualizaba y acotaba de forma artificial, distribuyéndolo y articulándolo en función de las artes militares del momento, aún en aquellos casos en los que se construyó sobre los antiguos poblados castreños.

Estas fortalezas no son de gran envergadura en cuanto a sus dimensiones, dotación y complejidad defensiva se refiere, siendo quizá una excepción el propio castillo de Aguiar, que al final de la Edad Media adquiere el significativo nombre de A Cidá, topónimo que aún se conserva en la actualidad.
Desde un punto de vista formal sorprende la simplicidad del castillo altomedieval de Litoria que aprovechaba la infraestructura arquitectónica del castro preexistente, limitándose a levantar un nuevo reducto terrero en la parte más alta e inaccesible del asentamiento. Por contraste en los castillos de Penedos de O Castro y de Aguiar, la intervención constructiva es mucho más notoria y transformadora, estando compartimentados en recintos dispuestos en distintos niveles, defendidos por murallas de piedra más espesas y sólidas trabadas con morteros de barro, que presentan lienzos rectilíneos y con el refuerzo en el caso de Penedos de $\mathrm{O}$ Castro de al menos un cubo saliente, que supone la incorporación de nuevos criterios de defensa activa. Todo ello denota unos parámetros técnicos más avanzados, en cuanto a ingeniería militar se refiere, que están directamente relacionados con el desarrollo de la artillería y con la invención de armas como la ballesta con mayor alcance de tiro, lo que nos lleva al pleno medioevo.

Igualmente, el registro arqueológico muestra que la nómina de fortalezas medievales resulta ser notablemente más numerosa de lo que encontramos en la documentación escrita, habiendo en el caso de la tierra de Aguiar una concentración notable y poco usual de este tipo de asentamientos, que encontraría explicación atendiendo a causas socioeconómicas y administrativas, pudiendo ser síntoma de un minifundismo jurisdiccional en el espacio geográfico circundante.

En relación con esto último hay que decir que en el siglo XI se observan en Búbal readaptaciones de las estructuras territoriales, con cambios en la concepción y percepción del espacio que parecen obedecer a distintas coyunturas políticas, de modo que ya en los siglos XII y XIII el panorama es sustancialmente diferente. Así, coincidiendo con cierto fortalecimiento del poder regio, el antiguo territorio se compartimentó en tierras de menor extensión, al tiempo que se restringieron ostensiblemente sus límites en favor de A Limia.

Surge entonces la tierra de Aguiar entre otras más que comprendían igualmente el ámbito espacial del antiguo territorio de Búbal. Al frente de estas tierras y sus castillos aparecerán distintos miembros de la nobleza ligados de un modo u otro a la monarquía, que representaban y ejecutaban el poder regio en su calidad de tenentes.

Hasta el final de Edad Media el castillo de Aguiar capitaneará nueva la tierra asumiendo 
atribuciones jurisdiccionales propias del sistema de tenencias. Este castillo, en principio conferido por los monarcas a título precario, pasó finalmente a manos de la nobleza, constituyendo un ejemplo paradigmático de cómo el ejercicio de una práctica de clara orientación feudalizante, como es la transferencia del poder público, supuso a largo plazo la fragmentación de los espacios de realengo, de modo que la jurisdicción regia acabaría por desmembrarse en señoríos nobiliarios, siendo las instituciones eclesiásticas las grandes beneficiarias del reparto en Galicia.

Así mismo, el caso de Aguiar ejemplifica los enfrentamientos que se produjeron por ignorar conscientemente los nobles laicos los privilegios que los monasterios venían ejerciendo en sus propias demarcaciones. Ejemplifica también el modo en que esos mismos nobles participaron en los bienes eclesiásticos mediante el aprovechamiento de su situación al frente de los mecanismos de la administración, consiguiendo en numerosas ocasiones hacerse con el control y el dominio pleno de las tierras y castillos que estaban de facto sujetos a su mando, tanto de forma ilegítima como en el caso ya mencionado de García Díaz de Cadórniga, como de manera legítima como hizo Juan Pimentel.

Este último personaje pertenecía a uno de los linajes de la nobleza trastamarista que junto con los Osorio, los Biezma, los Zuñiga y los Sarmiento, se fueron implantando en el sur de Galicia en los siglos finales de la Edad Media, amparados por la nueva dinastía mediante el reconocimiento de títulos, cargos y donaciones, de modo que fueron incrementando sus posesiones y el número de sus fortalezas en virtud de las alianzas matrimoniales, compras, foros, presentaciones de feligresías y tenencias. Con frecuencia lograron imponerse en los señoríos eclesiásticos y concejiles mediante la práctica de la encomienda, con miras al acaparamiento y usurpación de sus recursos económicos como única opción factible ante la falta de espacios libres. Algunas ramas familiares pertenecientes a estos linajes llegaron a reunir importantes conglomerados patrimoniales, que en determinados casos constituyeron auténticos estados señoriales que pervivieron a lo largo de la Edad Moderna. Junto a ellos surgió un número creciente de hidalgos locales, que medraron a su sombra.

Así pues, aun con sus peculiaridades, podemos decir que la evolución del territorio de Búbal y de la tierra de Aguiar se incardinan sin mayores discrepancias en el proceso general de la progresiva feudalización experimentada por la sociedad gallega del medioevo. Proceso que encuentra su máxima expresión en las propias fortalezas, símbolos por excelencia del poder vigente que se imponían sobre el paisaje cumpliendo con funciones polivalentes más allá de las estrictamente militares, en respuesta sin duda a las amenazas externas y también a las luchas y disputas internas, sirviendo de protección de unos señores contra otros y siendo moneda de cambio en alianzas y tratados, pero las fortalezas son, sobre todo, instrumentos decisivos en el control del espacio y de la propia población, jugando un papel determinante en la estructuración social y en la organización territorial.

\section{Referencias bibliográficas}

Andrade Cernadas, José Miguel (1995): O Tombo de Celanova: Estudio introductorio, edición e índices. Santiago de Compostela: Consello da Cultura Galega.

Arias Sanjurjo, Joaquín (1932): El castillo de Litoria y otras menudencias orensanas. Santiago de Compostela: Tip. Paredes.

Balil Illana, Alberto; Gerardo Pereira Menaut y Francisco Javier Sánchez-Palencia Ramos (eds.) (1991): Tabula Imperii Romani. Hoja K-29: Porto. Conimbriga-Bracara-Lucus-Asturica. Madrid: Unión Académica Internacional (Comité español) / Instituto Geográfico Nacional.

Baliñas Pérez, Carlos (1992): Do mito á realidade. A definición social e territorial de Galicia na alta Idade Media (séculos VIII e IX). Santiago de Compostela: Fundación Universitaria de Cultura.

Barroca, Mário Jorje (1994): Do castelo da reconquista ao castelo románico, séc IX a XII. Lisboa: Comissão Port. de História Militar.

Blanco González, X. A. y X. M. Rodríguez Pereira, (1991): “Localización do emplazamento do Castelo de Litoria", O Rumor da Fraga 1, pp. 13-24.

Blanco González, X. A., X. R. Dorribo y X. M. Rodríguez Pereira (1992): “Coto de San Estevo (Nogueira de Ramuín)", O Rumor da Fraga 3, pp. 9-15.

Bouzas Rosende, Paula (2016): Documentos galegos do mosteiro de Santo Estevo de Ribas de Sil. Siglo XV. Santiago de Compostela: Consello da Cultura Galega. 
Cambón Suárez, Segundo (1957): El Monasterio de Santa María de Melón (s. XII-XIII). Tesis doctoral inédita. Santiago de Compostela: Universidade de Santiago de Compostela.

Cardim, Pedro; Luis Adão da Fonseca y Carlos Andrés González Paz (2014): "Fronteira/Fronteiras e identidade. A perspectiva galega", en L. Adão da Fonseca (coord.), Entre Portugal e a Galiza (sécs. XI a XVII). Un olhar peninsular sobre uma região histórica. Porto: Centro de Estudos da População, Economia e Sociedade / Fronteira do Caos, pp. 231-242.

Castillo López, Ángel del (1930): "El castillo de Litoria”, Boletín de la Real Academia Gallega 19, pp. 277-287.

Castro, Manuel y Manuel Martínez Sueiro (trans.) (1923): Documentos del Archivo de la Catedral de Orense. Ourense: Comisión de Monumentos de Orense.

David, Pierre (1947): Études historiques sur la Galice et le Portugal du VIe au XIIe siecle. Lisboa: Institut Français au Portugal (Collection Portugaise, 7).

Díaz y Díaz, Manuel; María Virtudes Pardo Gómez y Daría Vilariño Pintos (eds.) (1990): Ordoño de Celanova: Vida y milagros de san Rosendo. A Coruña: Fundación Pedro Barrié de la Maza.

Duro Peña, Emilio (1968): "El monasterio de Santa Comba de Naves", Anuario de Estudios Medievales 5, pp. 137-176.

(1972): El monasterio de San Pedro de Rocas y su colección documental. Ourense: Instituto de Estudios Orensanos "Padre Feijoo".

(1977): El monasterio de San Esteban de Ribas de Sil. Ourense: Instituto de Estudios Orensanos "Padre Feijoo".

(1996): Documentos da catedral de Ourense. 2 vols. Santiago de Compostela: Consello da Cultura Galega.

Eguileta Franco, Xosé María y Manuel García Valdeiras (1997): Fichas GA32052001, GA32052006, GA32052015, GA32052017, GA32052019 del Inventario de Xacementos Arqueolóxicos da Xunta de Galicia.

Eguileta Franco, Xosé María; Celso Rodríguez Cao y Manuel Xusto Rodríguez (1991): “Arqueoloxía na Baixa Limia. O encoro de Lindoso e o seu entorno: Lobios (Ourense)", en Arqueoloxía. Informes 2: Campaña 1988. Santiago de Compostela: Xunta de Galicia, pp. 139-156.

Eguileta Franco, Xosé María y Manuel Xusto Rodríguez (1995): "Prospección e escavación arqueolóxica na Baixa Limia. O encoro de Lindoso e o seu entorno (Ourense)", en Arqueoloxía Informes 3. Campaña 1989, pp. 107-114.

Enjo Babío, María Ascensión (2018): Colección documental del archivo de la catedral de Ourense (s. $X I V)$. Santiago de Compostela: CSIC, Instituto de Estudios Gallegos Padre Sarmiento (Cuadernos de Estudios Gallegos, Anexo 46), 2 vols.

Fariña Busto, Francisco (1991): "Dos notas a propósito de Castromao (Celanova, Ourense)", Cuadernos de Estudios Gallegos 39, n 104, pp. 57-71.

Fernández de Viana y Vieites, José Ignacio (2009): Colección diplomática do mosteiro de San Pedro de Vilanova de Dozón. Santiago de Compostela: Consello da Cultura (Fontes para a Historia de Galicia, 11).

Ferreira de Almeida, Carlos Alberto (1978): Castelología Medieval de Entre-Douro e Minho. Porto: Ed. Autor.

Ferreira Priegue, Elisa (1988): Los caminos medievales de Galicia. Ourense: Museo Arquelóxico Provincial (Boletín Auriense, Anexo 9).

Ferro Couselo, Xesús (trans.) (1995): Tumbo de Fiães. Ourense: Museo Arqueolóxico Provincial (Boletín Auriense, Anexo 20).

Freire Camaniel, José (1988-89): “¿Un testimonio epigráfico de la existencia en Orense de un ‘duque’ de Leovigildo?", Boletín Auriense 18-19, pp. 133-142.

- (1998): El monacato gallego en la Alta Edad Media. Tomo 2. A Coruña: Fundación Pedro Barrié de la Maza.

García de Cortázar, José Ángel (2004): Sociedad y organización del espacio en la España medieval. Granada: Universidad de Granada (Biblioteca de Bolsillo, 31).

García Quintela, Marco Virgilio (2002): La organización socio-política de los populi del Noroeste de la Península Ibérica. Un estudio de antropología política histórica comparada. Santiago de Compostela: Laboratorio de Patrimonio, Paleoambiente e Paixase (TAPA. Traballos de Arqueoloxía e Patrimonio 28). 
García Rodicio, Antonio (1977): "Vía Romana de Astorga a Orense por el Castro Litoria", Boletín Auriense 25 , pp. 122-127.

García Tato, Isidro (2001): O Bolo y Viana do Bolo, dos jurisdicciones de realengo. Santiago de Compostela: Gráficas Loureiro.

García Valdeiras, Manuel (2013): Escavación arqueolóxica en Os Penedos do Castro (Nogueira de Ramuín, Ourense) 1999, 2000, 2001, 2007. Memoria técnica final inédita. Depositada en el Servicio de Arqueoloxía da Xunta de Galicia.

González Balasch, María Teresa (2004): El Tumbo B de la Catedral de Santiago. Santiago de Compostela: Cabildo de la S.A.M.I. Catedral / Seminario de Estudios Galegos (Colección Histórico-Documental de la Iglesia Compostelana, 3).

González González, Julio (1944): Alfonso IX. 2 vols. Madrid: CSIC.

González Paz, Carlos Andrés (2007): "Catro exemplos de fortificacións altomedievais galegas do seculo X: Castellum de Aranga, Castellum Minei, Castellum Berreti e castellum de Citofacta", en Francisco Singul (dir.), Rudesindus: "San Rosendo. O seu tempo e o seu legado". Congreso Internacional. Mondoñedo, Santo Tirso (Portugal) e Celanova 27-30 de Xuno, 2007. Santiago de Compostela: Xunta de Galicia, 2007, pp. 359-368, http://hdl.handle.net/10261/23122.

González Vázquez, Marta (1996): El Arzobispo de Santiago, una instancia de poder en la Edad Media (1150-1400). Sada: Ediciós do Castro (Publicacións do Seminario de Estudos Galegos, 1).

Gutiérrez González, José Avelino (1995): Fortificaciones y feudalismo en el origen y formación del reino leonés (siglos IX-XIII). Valladolid: Universidad de Valladolid.

Isla Frez, Amancio (1992): La sociedad gallega en la Alta Edad Media. Madrid: CSIC (Biblioteca de Historia, 12).

Jular Pérez-Alfaro, Cristina (1991): “Alfoz y Tierra a través de documentación castellana y leonesa de 1157 a 1230. Contribución al estudio del dominio señorial”, Studia Histórica 9, pp. 9-42.

López Ferreiro, Antonio (1904): Historia de la Santa A. M. Iglesia de Santiago de Compostela, vol. 7. Santiago de Compostela: Seminario Conciliar Central Compostelano.

(1975): Fueros municipales de Santiago y de su tierra. Madrid: Ediciones Castilla.

López Sangil, José Luis y Manuel Vidán Torreira (2011): "El Tumbo Viejo de Lugo", Estudios Mindonienses 27 , pp. 11-373.

Loscertales de G. de Valdeavellano, Pilar (1976): Tumbos del monasterio de Sobrado de los Monjes. Madrid: Dirección General del Patrimonio Artístico y Cultural / Archivo Histórico Nacional, 2 vols.

Lucas Álvarez, Manuel (1986): El tumbo de San Julián de Samos (siglos VIII-XII). Estudio introductorio. Edición diplomática. Apéndices e indices. Santiago de Compostela: Obra Social de Caixa Galicia.

Lucas Álvarez, Manuel y Pedro Pablo Lucas Domínguez (1988): San Pedro de Ramirás, un monasterio femenino en la Edad Media. Colección diplomática. Santiago de Compostela: Obra Social de Caixa Galicia.

- (1996): El priorato benedictino de San Vicenzo de Pombeiro y su colección diplomática en la Edad Media. Sada: Ediciós do Castro.

Marques, José (2016): O cartulario do mosteiro de Fiães (ADB, Ms. 1052). Melgaço (Portugal): Câmara Municipal, 2 vols.

Marquina y Álvarez, Eugenio (1907): "Documentos históricos", Boletín de la Comisión Provincial de Monumentos Históricos y Artísticos de Orense 3/57, p. 175.

Mora-Figueroa Dingwillians, Luis de (1994): Glosario de arquitectura defensiva medieval. Cádiz: Universidad de Cádiz / Ministerio de Defensa.

Orero Grandal, Luis (2000): "Castromao (Celanova, Ourense)", Brigantium. Boletín do Museu Arqueolóxico e Histórico da Coruña 12, pp. 179-185.

(2001): "Os castros da Terra de Celanova: Castromao como paradigma", en J. M. Eguileta Franco, L. Orero Grandal y L. Castro Pérez (eds.), Arqueoloxía prehistórica na Terra de Celanova. Celanova: Concello de Celanova, pp. 155-168.

Pardo de Guevara y Valdés, Eduardo; César Olivera Serrano, Carlos González Paz y Rosario Valdés Blanco-Rajoy (2007): "El inventario documental y gráfico de las fortalezas medievales de Galicia. Método de trabajo y avance de resultados (1995-2006)", en M. López-Mayán Navarrete y C. J. Galbán Malagón (coords.), Del documento escrito a la evidencia material. Actas del I Encuentro Compostelano de Arqueología Medieval (Santiago de Compostela, 22, 23 y 24 de marzo de 2006). Santiago de Compostela: Lóstrego, pp. 115-139. 
Pena Graña, Andrés (1991): Narón, un concello con historia de seu. Narón: Concello de Narón. (2007) "Galicia, cuna de los celtas de la Europa Atlántica", Anuario Brigantino 30, pp. 57-88.

Pérez Losada, Fermín (2002): "Entre a cidade e a aldea. Estudio arqueohistórico dos 'aglomerados secundarios' romanos en Galicia”, Brigantium. Boletín do Museu Arqueolóxico e Histórico da Coruña 13, pp. $15-348$.

Pérez Rodríguez, Francisco Javier (2015): "El coto auriense y el castillo de Louredo entre las tierras de Búbal y Limia (ss. X-XII)”, Minius 23, pp. 241-260.

Pichel Gotérrez, Ricardo (2009): Fundación e primeiros séculos do mosteiro bieito de Santo Estevo de Chouzán (sécs. IX-XIII). Noia: Editorial Toxosoutos (Serie Trivium, 36).

Recuero Astray, Manuel; Marta González Vázquez y Paz Romero Portilla (1998): Documentos medievales del reino de Galicia. Alfonso VII (1116-1157). Santiago de Compostela: Xunta de Galicia.

Recuero Astray, Manuel; Paz Romero Portilla y Ma Ángeles Rodríguez Prieto (2000): Documentos medievales del reino de Galicia: Fernando II (1155-1188). Santiago de Compostela: Xunta de Galicia.

Rodríguez Cao, Celso (1995): Ficha GA32047011 del Inventario de Xacementos Arqueolóxicos da Xunta de Galicia.

Rodríguez Cao, Celso y Manuel García Valdeiras (1999): Ficha GA32058006 del Inventario de Xacementos Arqueolóxicos da Xunta de Galicia.

Rodríguez Colmenero, Antonio (1977): Galicia meridional romana. Bilbao: Universidad de Deusto.

(1995): "Corpus de inscripciones rupestres de época romana del cuadrante Noroeste de la península Ibérica”, en A. Rodríguez Colmenero y L. Gasperni (eds.), Saxa Scripta (Inscripciones en Roca). Actas del Simposio Internacional Ibérico Itálico sobre epigrafía rupestre. Sada: Ediciós do Castro, pp. 233237 (Larouco, Anejo 2).

(1997): “A organización socio-política do espacio: etnias e territorio”, en J. M. García Iglesias (ed.), Galicia castreña y romana. Santiago de Compostela: Consellería de Cultura e Comunicación Social, pp. 85-91.

Rodríguez González, Ángel (1984): Las fortalezas de la mitra compostelana y los “irmandiños”. Pleito Tabera-Fonseca. A Coruña: Fundación Pedro Barrié de la Maza / Instituto Padre Sarmiento de Estudios Gallegos, 2 tomos.

(1995): O Tumbo Vermello de Don Lope de Mendoza. Santiago: CSIC, Instituto Padre Sarmiento de Estudios Gallegos (Cuadernos de Estudios Gallegos, Anexo 23).

Romalde Purriños, Juan Francisco y Matilde González Méndez (1991): Fichas GA32052001, GA32052006, GA32052015, GA32052017, GA32052019 del Inventario de Xacementos Arqueolóxicos da Xunta de Galicia.

Romaní Martínez, Miguel (dir.) (1989-2008): Colección diplomática do mosteiro cisterciense de Santa María de Oseira (Ourense). Santiago de Compostela: Tórculo, 5 vols.

Sáez Sánchez, Emilio (1944): "El monasterio de Santa María de Ribeira”, Hispania. Revista Española de Historia 4/14-15, p. 168.

Sáez Sánchez, Carlos y Mª del Val González de la Peña (2003): La Coruña: fondo antiguo (788-1065). Vol. 1. Madrid: Universidad de Alcalá (Galicia, 3).

Sáez Sánchez, Emilio y Carlos Sáez Sánchez (1996): Colección diplomática del monasterio de Celanova (842-942). Vol. 1. Madrid: Universidad de Alcalá (Galicia, 1).

(2000): Colección diplomática del monasterio de Celanova (843-988). Vol. 2. Madrid: Universidad de Alcalá (Galicia, 2).

Sánchez Arcilla Bernal, José (2002): "La administración de justicia en León y Castilla durante los siglos $\mathrm{X}$ al XIII", en Á. Riesco Terrero (coord.), I Jornadas sobre documentación jurídico-administrativa, económico-financiera y judicial del reino castellano-leonés (siglos X-XIII). Madrid: Universidad Complutense, pp. 13-49.

Sánchez Candeira, Alfonso (1999): Castilla y León en el siglo XI. Estudio del reinado de Fernando I. Madrid: Real Academia de la Historia.

Sánchez Pardo, José Carlos (2008): Territorio y poblamiento en Galicia entre la Antigüedad y la plena Edad Media. Tesis doctoral. Santiago de Compostela: Universidade de Santiago de Compostela, https:// minerva.usc.es/xmlui/handle/10347/2451.

Seara, Alfredo y Carmen Cabo (1986): Ficha GA32031002 del Inventario de Xacementos Arqueolóxicos da Xunta de Galicia. 
Seara, Alfredo e Isabel Peralta (1989): Ficha GA32031002 del Inventario de Xacementos Arqueolóxicos da Xunta de Galicia.

Serrano y Sanz, Manuel (1929): "Documentos del monasterio de Celanova", Revista de Ciencias Jurídicas y Sociales $12 / 46$ y 49 , pp. 5-47, 512-524.

Taboada Chivite, Jesús (1955): “Carta arqueológica de la comarca de Verín”, en III Congreso Nacional de Arqueología. Galicia 1953. Zaragoza: Institución Fernando el Católico / CSIC (Publicaciones del Seminario de Arqueología y Numismática Aragonesa, 161).

Tranoy, Alain (1981): La Galice Romaine. Recherches sur le nord-ouest de la péninsule ibérique dans l'Antiquité. París: Difussion de Boccard (Publications du Centre Pierre París 7 / Collection de la Maison des Pays Ibériques 7).

Vaquero Díaz, Ma Beatriz y Francisco Javier Pérez Rodríguez (2010): Colección documental del Archivo de la Catedral de Ourense. 2 vols. León: Centro de Estudios e Investigación "San Isidoro" / Caja España de Inversiones / Archivo Histórico Diocesano (Fuentes y Estudios de Historia Leonesa, 132).

Vázquez Núñez, Arturo (1900): "El monasterio de Ribas de Sil", Boletín de la Comisión Provincial de Monumentos Históricos y Artísticos de Orense 1/15, p. 273.

(1901) "Documentos históricos", Boletín de la Comisión Provincial de Monumentos Históricos y Artísticos de Orense 1/20, pp. 378-379.

(1903) "Documentos históricos", Boletín de la Comisión Provincial de Monumentos Históricos y Artísticos de Orense 2/33, p. 169. 
